\title{
A Support Vector Machine Learning-Based Protection Technique for MT-HVDC Systems
}

\author{
Raheel Muzzammel *(i) and Ali Raza *(D) \\ Department of Electrical Engineering, University of Lahore, Lahore 54000, Pakistan \\ * Correspondence: raheel.muzzammel@ee.uol.edu.pk (R.M.); ali.raza@ee.uol.edu.pk (A.R.)
}

Received: 17 November 2020; Accepted: 11 December 2020; Published: 17 December 2020

\begin{abstract}
High voltage direct current (HVDC) transmission systems are suitable for power transfer to meet the increasing demands of bulk energy and encourage interconnected power systems to incorporate renewable energy sources without any fear of loss of synchronism, reliability, and efficiency. The main challenge associated with DC grid protection is the timely diagnosis of DC faults because of its rapid built up, resulting in failures of power electronic circuitries. Therefore, the demolition of HVDC systems is evaded by identification, classification, and location of DC faults within milliseconds (ms). In this research, the support vector machine (SVM)-based protection algorithm is developed so that DC faults could be identified, classified, and located in multi-terminal high voltage direct current (MT-HVDC) systems. A four-terminal HVDC system is developed in Matlab/Simulink for the analysis of DC voltages and currents. Pole to ground and pole to pole faults are applied at different locations and times. Principal component analysis (PCA) is used to extract reduced dimensional features. These features are employed for the training and testing of SVM. It is found from simulations that DC faults are identified, classified, and located within $0.15 \mathrm{~ms}$, ensuring speedy DC grid protection. The realization and practicality of the proposed machine learning algorithm are demonstrated by analyzing more straightforward computations of standard deviation and normalization.
\end{abstract}

Keywords: DC grid protection; MT-HVDC transmission systems; fault identification; fault classification; fault location; support vector machine (SVM); principal component analysis (PCA); standard deviation (SD); normalization $(\mathrm{N})$

\section{Introduction}

Intercontinental super-grid and integration of a large number of renewable energy sources to the conventional grid are the fruitful developments achieved through the promising technology of multi-terminal high voltage direct current (MT-HVDC) transmission systems [1-3]. Most of the renewable energy sources are located far from load centers, and therefore, the transfer of energy must be done effectively [4]. For example, an offshore super-grid will be inevitable in the future for the interconnection of offshore wind farms of Northern Europe and the United Kingdom [5]. Similarly, solar installations in Africa's deserts can only be connected to load centers of Europe and Asia via MT-HVDC grids [5].

The MT-HVDC system's technical and economic feasibility is proved by recent developments in voltage source converters (VSCs) and DC circuit breakers [6]. However, there is still a challenge in expanding point-point HVDC systems to MT-HVDC systems, i.e., developing reliable and quick protection systems to interrupt the abrupt rise of DC fault currents. In the literature, HVDC point-point links are interrupted from the AC side of the converter station if DC fault persists [6], which results in the shutdown of the entire DC system [7]. Thus, this technique is not recommended for MT-HVDC systems because of the tripping of healthy links along with faulted circuits. Therefore, it is always desired to develop (i) an appropriate relaying mechanism and (ii) HVDC circuit breakers for the 
isolation of faulty circuits only [2,5]. Moreover, an accurate and abrupt action of relaying mechanisms is responsible for the online adjustment of zonal relay settings, planned maintenance of the faulty line, and restoring the system without any fear of tripping instants [2].

Initially, S. Agarwal et al. diagnosed the transmission systems' faults through impedance-based methods [8]. But the accuracy of fault estimation decreases with the increase in distance of fault from sensing location [8]. Advancement in transducer technology leads to developing a fault diagnostic technique based on current and voltage samples [9-12]. However, advanced filtering methods of eradicating fault-loop impedance are required for electrical noise [13].

The inventions of fast analog to digital conversions and numerical relays have introduced traveling wave (TW)-based protection methods in both AC and DC systems [14-22]. However, the unavailability of mathematical tools to model TW, the difference in the velocities of TWs in overhead line and underground cables, the incomplete information of surge impedance, and the high sampling rate are the hurdles in real-time implementation $[18,23,24]$.

Voltage wavelet analysis, current wavelet analysis, and voltage derivative and magnitude analysis are proposed in [24] as three independent DC fault diagnosis criteria. Fault detection time increases with the increase in fault resistance, the drawback [25]. The transient based protection is designed for DC-grids in $[24,26]$. In this technique, smoothing reactors and capacitors are deployed at ends of DC links. Inherent busbar capacitance does not transmit high-frequency signals, employed for discrimination between internal and external faults [18]. This method may experience mal-operation due to non-fault transients in lightning events [26]. A low speed relaying mechanism is proposed for mechanical DC breakers in [27]. The total fault clearing time is $1 \mathrm{~min}$, not acceptable for MT-HVDC systems [27]. The hybrid protection is based on stationary wavelet transform and traveling waves proposed in [18] for HVDC systems to discriminate between fault-transient and non-fault lightning transient events [18]. Faults closed to the converter stations, which cannot be detected by TW methods, can readily be detected with hybrid techniques. However, it requires expensive hardware for a high sampling rate. The differential analysis of high-frequency transients in current signals, measured at each terminal, is introduced to protect MT-HVDC systems [28]. This method requires reliable communication between terminals/VSCs of the DC transmission lines and offers inherent latency [29].

Artificial neural networks (ANN)-based methods are found beneficial in fault diagnosis because of their accuracy [30,31], robustness [32], and speed [30,31] in HVDC systems [33,34]. ANN-based techniques are often supported with feature selection through the Fourier transform or wavelet transform [35,36], but it has drawbacks such as: Inaccurate fault diagnosis with incomplete information and demands for advanced mathematical tools for feature selection through transform procedures [37,38].

The techniques mentioned above pose shortcomings to DC grid protection such as: (i) Inaccurate, (ii) not robust, (iii) impose electrical noise, (iv) slow in response, (v) complex calculations, and (vi) requirement of expensive signal processing tools. Thus a machine learning (ML) technique, support vector machine (SVM) based algorithm [39-41], is developed in this paper to overcome the abovementioned obstacles. Support vector machine (SVM) based fault detection, classification, and location have not been conducted/explored in literature for MT-HVDC systems. The development of a rapid and mature protection scheme is the main challenge in MT-HVDC systems to ensure successful and appropriate interruption of the DC breaker in the event of a fault [42,43].

In this research, an algorithm based on support vector machine (SVM) learning is developed for fault diagnosis in MT-HVDC systems. Features extracted through principal component analysis (PCA) are employed for training and testing of SVM. The proposed protection algorithm is applied to the four-terminal HVDC test system. Various types of faults are created at different locations in the DC test system. This algorithm successfully identifies, classifies, and locates the DC faults. This proposed algorithm is robust, requires less computational time, and is accurate even for the DC faults closed to the VSC stations. Thus, the proposed SVM-based algorithm overcomes the shortcomings of all the aforementioned protection techniques of the literature 
Moreover, the SVM based analysis of standard deviation and normalization is added to demonstrate the realization of fault diagnosis in a time frame of $0.15 \mathrm{~ms}$.

This research paper consists of the following sections: The mathematical formulation and proposed fault diagnostic algorithm based on the support vector machine is described in Section 2. MT-HVDC test system is explained in Section 3. Simulation results are discussed in Section 4. Main achievements are added in Section 5. Finally, conclusions are drawn in Section 6.

\section{Support Vector Machines (SVM)}

A support vector machine is a statistical supervised machine learning technique employed for both regression and classification. Vapnik and Cortes originally developed it in 1995 [44,45]. Although this technique differs from ANN, some authors sometimes declare SVM as a special type of ANN [46,47]. A rigorous mathematical and statistical approach is employed for the development of SVM [48-53]. Both binary and multi-class classification problems are the root cause of the development of its mechanism. In binary linear SVM, the optimal hyper-plane plays a decision-making role for classification between two classes based on training datasets. There are two ways to achieve the optimal classification of training datasets.

Hard margin optimality can be employed to achieve the perfect distinction between training datasets' classes, as shown in Figure 1. Maxima is derived from the hyper-plane decision boundary. It helps to maximize the distance between the hyper-plane and the nearest training data points.

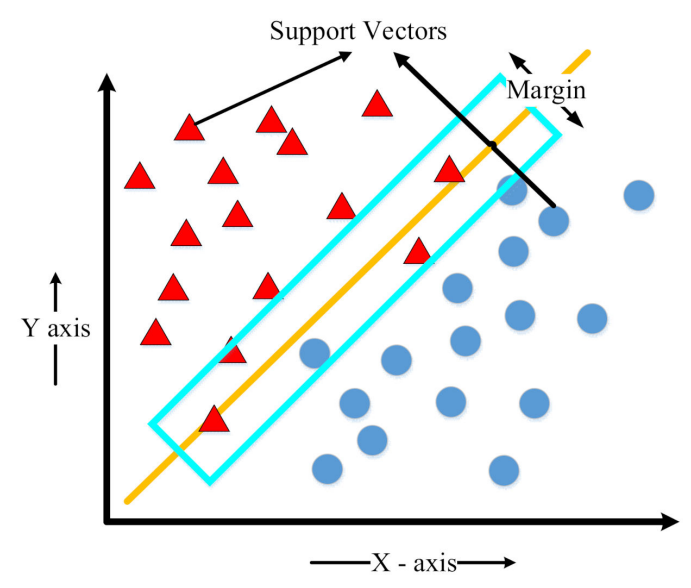

Figure 1. Binary classification based on support vector machine (SVM).

Soft margin optimality is employed if no perfect classification is required. Therefore, hyperplane plays a customized trade-off role between two relative extremes that are: Minimizing the failure (misclassification) rate and maximizing the distance between the hyperplane to the properly classified nearest training point.

In SVM classification, the decision boundary hyperplane is evaluated by support vectors. A different dataset can be applied to SVM classifier after the determination of the hyperplane. +1 or -1 is assigned to class depending on the location of the dataset concerning the decision boundary. In the case of a multi-class classification problem, as shown in Figure 2, different approaches, such as pairwise and one-versus-all, are employed to convert multi-class classification to binary-class classification [48]. In addition to this, reformulations of binary classification for compact multi-class classification problems are also developed in literature [54]. All the variables used in this research paper are enlisted in nomenclature section. 


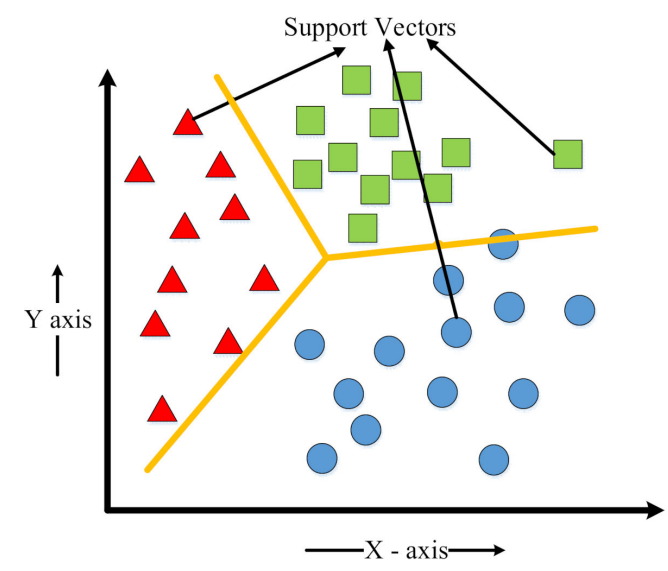

Figure 2. Multi-classification based on SVM.

\subsection{Mathematical Formulation}

The objective function of the SVM classification problem is given as:

$$
\phi(w, \xi)=\frac{1}{2} w^{T} w+C \sum_{i=1}^{N} \xi_{i}
$$

where $x_{i} \in \mathbb{R}^{m_{0}}$ is the $i$ th input vector, $d_{i} \in\{-1,1\}$ represents the class corresponding to the $i$ th input vector. $\xi=\left\{\xi_{i}\right\}_{i=1}^{N}$ is the slack variable. $C$ is a user-specified parameter that plays a trade-off role between misclassification and maximum inter-class margin. The minimum objective function, i.e., computation of optimal weight vector, should satisfy the following conditions:

$$
d_{i}\left(w^{T} x_{i}+b\right) \geq 1-\xi_{i}, \forall i=1,2, \ldots, N \xi_{i} \geq 0, \forall i=1,2, \ldots, N
$$

where $\left\{x_{i}, d_{i}\right\}_{i=1}^{N}$ is training data set, $w$ is weight vector, $b$ is bias, and $\xi$ is a slack variable.

Practically, it is impossible to solve all the classification problems by declaring a simple hyperplane as the decision boundary. Therefore, a more complex and dynamic decision boundary is required. In SVM, non-linear transformation is applied to increase the dimensions of the input space of dimensions $m_{0}$ to a feature space of dimensions $m_{f}>m_{0}$. As a result, the probability of misclassification in the transformed feature space is minimized. Radial basis functions, higher-order polynomials, and sigmoids are common transformation functions. In the non-linear classification problem, the hyperplane decision boundary is associated with feature space and given as:

$$
w^{T} \varphi(x)+b=0
$$

where $\varphi(x)$ is the point of transformed feature space, $x \in \mathbb{R}^{m_{o}}$ and $\varphi(x) \in \mathbb{R}^{m_{f}}$. Weight vector $w$ can be optimized by the Lagrange multipliers method [45] and given as:

$$
w=\sum_{i=1}^{N} \alpha_{i} d_{i} \varphi\left(x_{i}\right)
$$

where $\alpha_{i}$ represents the coefficients of the Lagrange multiplier. The decision boundary can be optimized by:

$$
\sum_{i=1}^{N} \alpha_{i} d_{i} \varphi\left(x_{i}\right)^{T} \varphi(x)+b=0
$$


Now with the assumption of $u_{i}=\alpha_{i} d_{i}$ and $K\left(x_{i}, x\right)=\varphi\left(x_{i}\right)^{T} \varphi(x)=\varphi(x)^{T} \varphi\left(x_{i}\right)=K\left(x, x_{i}\right)$, the optimized decision function $y$ is simplified as:

$$
y=\sum_{i=1}^{N} u_{i} K\left(x, x_{i}\right)+b
$$

In the scenario of linear classification, $K\left(x, x_{i}\right)$ represents the traditional Euclidean inner product of the input vector $x$ with the support vector $x_{i}$. In the scenario of non-linear classification, $K\left(x, x_{i}\right)$ represents the traditional Euclidean inner product of the input vector $x$ with the linear transformation $\varphi\left(x_{i}\right)$ of the support vector $x_{i}$. The proposed flow chart of support vector machine-based classification is demonstrated in Figure 3.

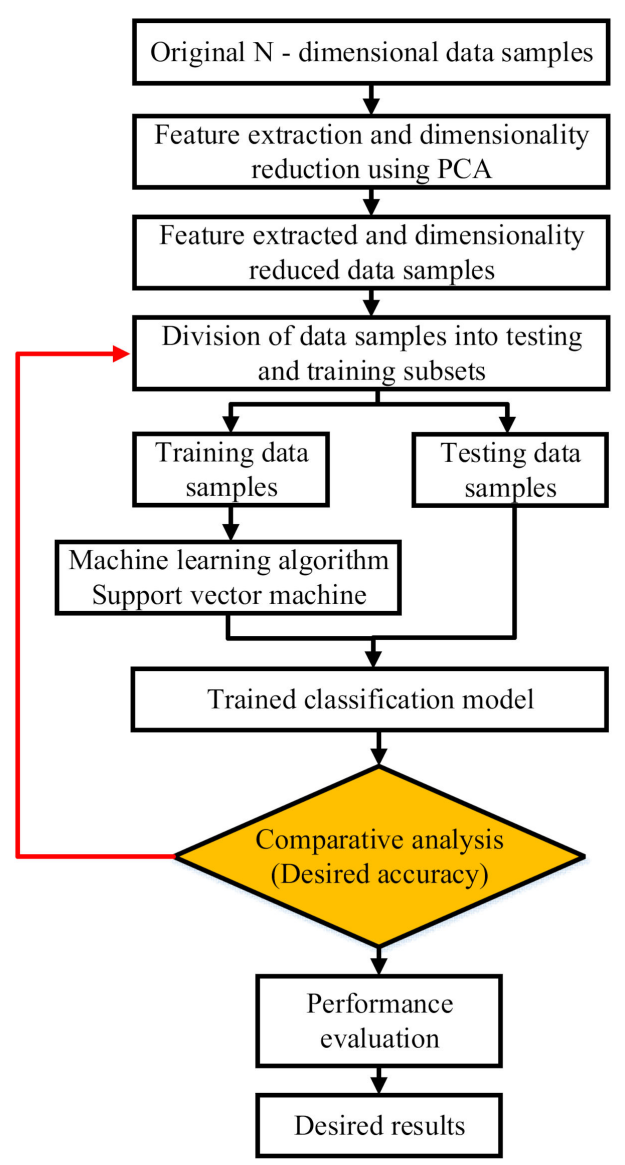

Figure 3. Proposed flow chart of SVM based classification.

\subsection{Principal Component Analysis (PCA)}

The principal component analysis is a statistical technique employed to study the inherent structure of the information. This method reduces the dimensions of data based on the rotation of coordinate axes. Eigenvalues and eigenvectors are produced from eigenvalue decomposition for the representation of variation in the sensed information. Uncorrelated lower-dimensional information is extracted from a set of correlated high-dimensional information. PCA minimizes squared reconstruction error in dimensionality reduction. The sensed information is represented by a matrix $A\left(A \in \mathfrak{R}^{p \times q}\right)$ with $p$ raw samples (rows) and $q$ process variables (columns) and is expressed as:

$$
A=\left[a_{1}, \ldots, a_{p}\right]^{T}
$$


where $x_{i}$ is the $i$ th normalized sample column vector. Correlation is represented by covariance matrix Cov, expressed as:

$$
\operatorname{Cov}=\frac{A^{T} A}{(q-1)} .
$$

Eigenvalues of $C o v$ are decomposed, and $a$ can be represented by:

$$
a=a_{e}+a_{r}
$$

where $a_{e}$ and $a_{r}$ are the projection vectors of $a$ onto the principal component subspace and residual subspace, respectively. The projection vector of residual subspace $a_{r}$ aids in the identification of faults and can be described as:

$$
a_{r}=\left(I-E E^{T}\right)
$$

where $E \in \mathfrak{R}^{q \times k}$ consists of the former $k$ columns of the eigenvector matrix and its column vectors represent nonnegative real eigenvalues. The increasing magnitude of the corresponding eigenvalues are expressed as:

$$
0 \leq \lambda_{q} \leq \ldots \leq \lambda_{2} \leq \lambda_{1} .
$$

A parameter is defined as an indication of the identification of a fault. It determines whether the sensed data belongs to the particular fault type or not and is expressed as:

$$
S=\left\|a_{r}\right\|_{2} .
$$

\subsection{PCA-Based SVM}

Each sensed data consists of $g$ number of samples. Training of the PCA model is conducted with a random selection of $h$ samples $(h<g)$ for each dataset. The rest of the samples are used to evaluate the accuracy of PCA-based features. The following are the steps behind the identification and classification of faults based on data obtained from multiple sensing terminals:

1. Sensed data obtained from different sensing terminals are employed as input.

2. Data is normalized with zero mean and unit variance.

3. Eigenvalue decomposition is carried out for normalized data. Optimal principal components are determined by the employment of the Scree test [55] given as:

$$
\operatorname{Scr}\left(\lambda_{i}, C_{i}\right), i=1,2, \ldots, q
$$

where $S c r$ is used to minimize the number of principal components and determine the optimal components. Each q process variable is associated with communalities $C_{i}$. Scr $=1$, when $\lambda_{i}>1$ and $C_{i}>0.5$, otherwise $S c r=0$. In general, high eigenvalues based components are retained, and low eigenvalues based components are eliminated.

4. An indication $S$ is created based on the optimal principal components.

5. The indication is classified based on the model of SVM based $S_{i}$. PCA model is trained to extract each $S_{i}$. Indicators $\left\{S_{0}, S_{1}, S_{2}, S_{3}\right\}$ has the indexes $i=(0,1,2,3)$. In the process of training, $h$ samples of sensed data are used to prepare each indicator.

6. The proposed algorithm is terminated with the results of fault identification and classification.

\subsection{Proposed SVM-Based Protection Algorithm}

The flow charts of the proposed SVM based fault diagnostic technique for the positive pole to ground (PPG) fault, negative pole to ground (NPG) fault, and pole-to-pole (PP) fault in the MT-HVDC system are presented in Figures 4-9, respectively. DC voltage and currents are measured at different fault locations in the MT-HVDC system. Standard deviation (SD) and normalization (N) are the features 
extracted from the DC voltages and currents analysis. Relative minima and maxima of standard deviation and normalization are evaluated. Relative minima and maxima of SD and $\mathrm{N}$ are compared at different fault locations and for different fault types for identification, classification, and location of DC faults in MT-HVDC systems.

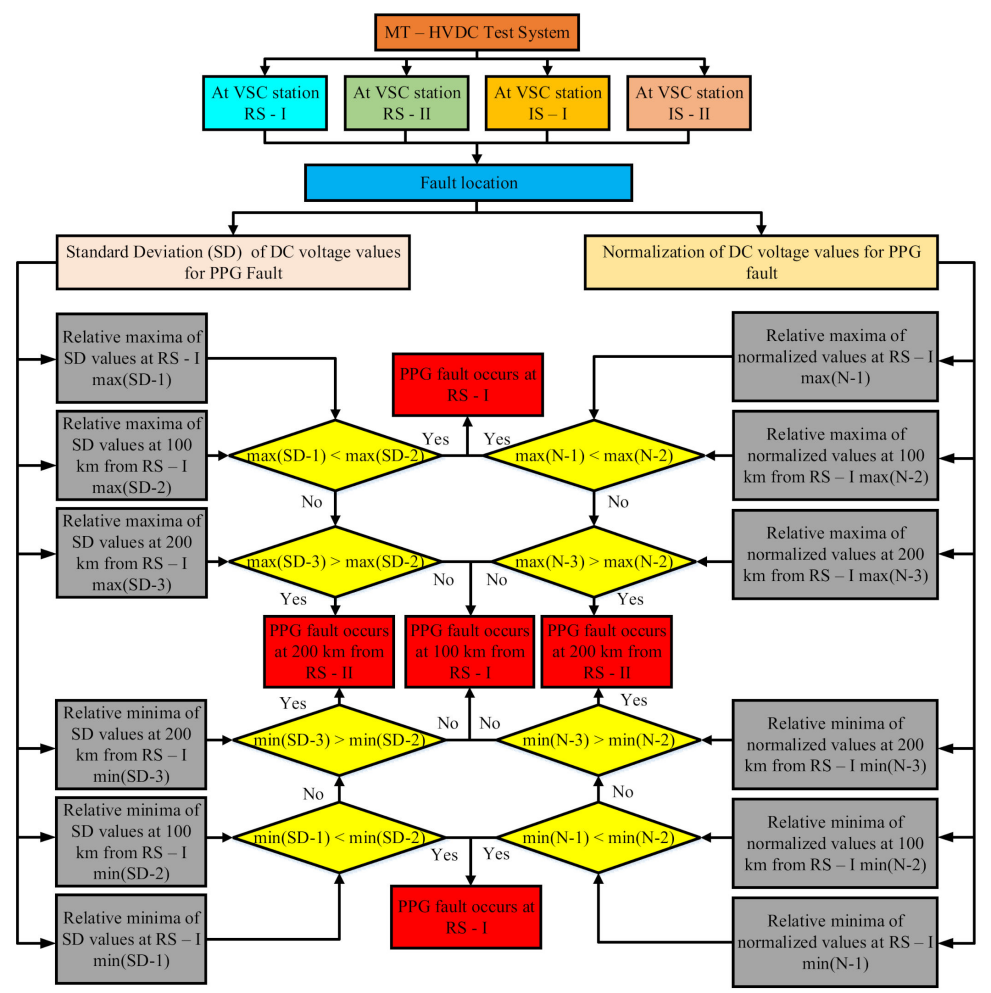

Figure 4. An algorithm for positive pole to ground (PPG) fault location finding based on SVM, using supported features of standard deviation and normalization of DC voltage.

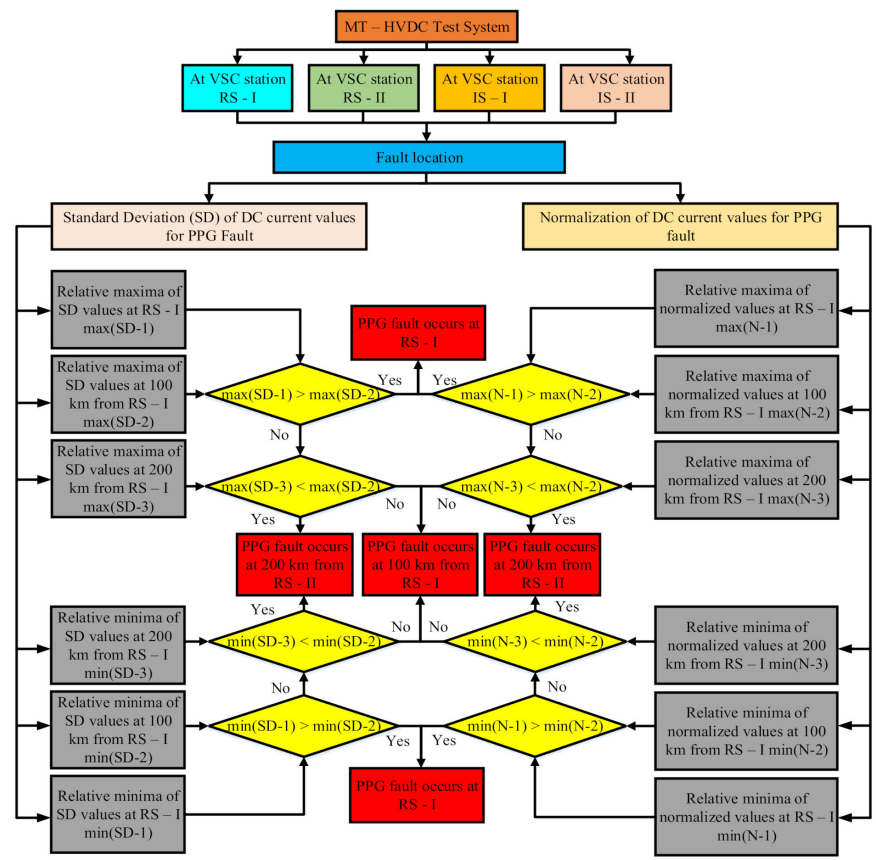

Figure 5. An algorithm for PPG fault location finding based on SVM, using supported features of standard deviation and normalization of DC current. 


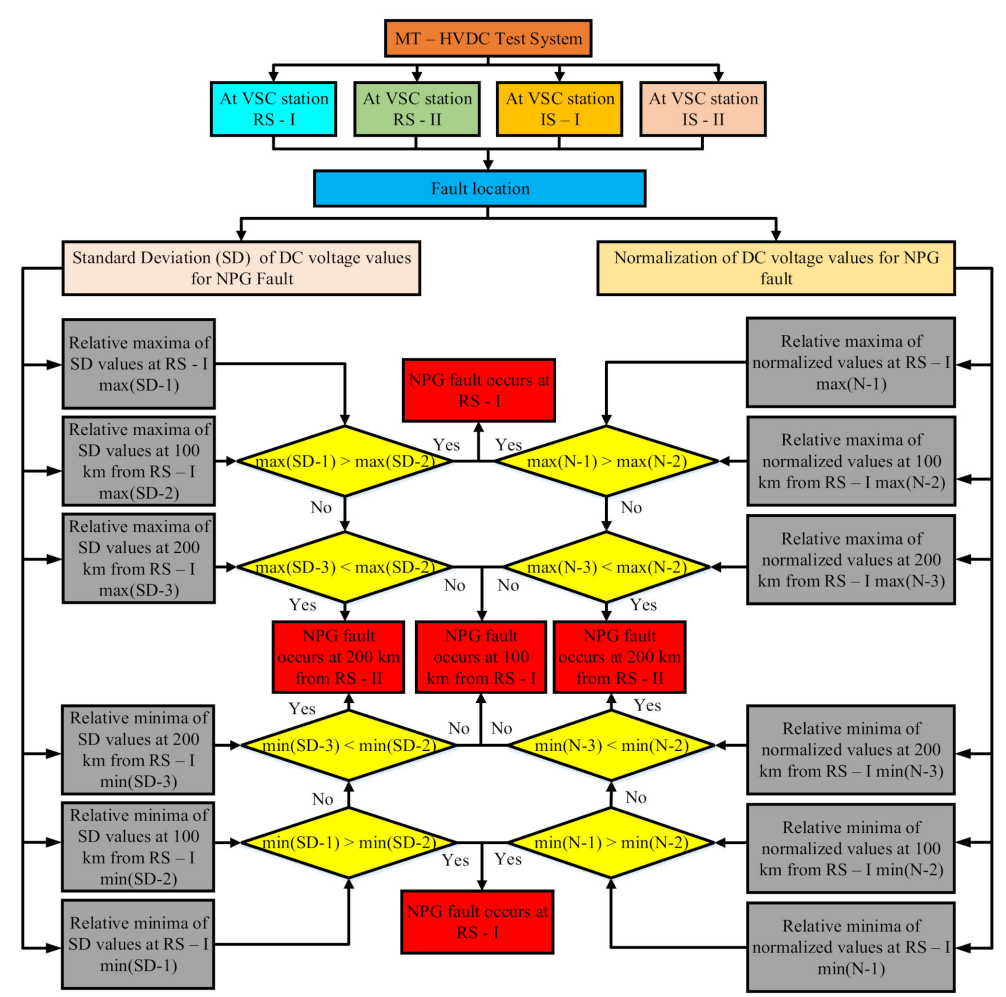

Figure 6. An algorithm for negative pole to ground (NPG) fault location finding based on SVM, using supported features of standard deviation and normalization of DC voltage.

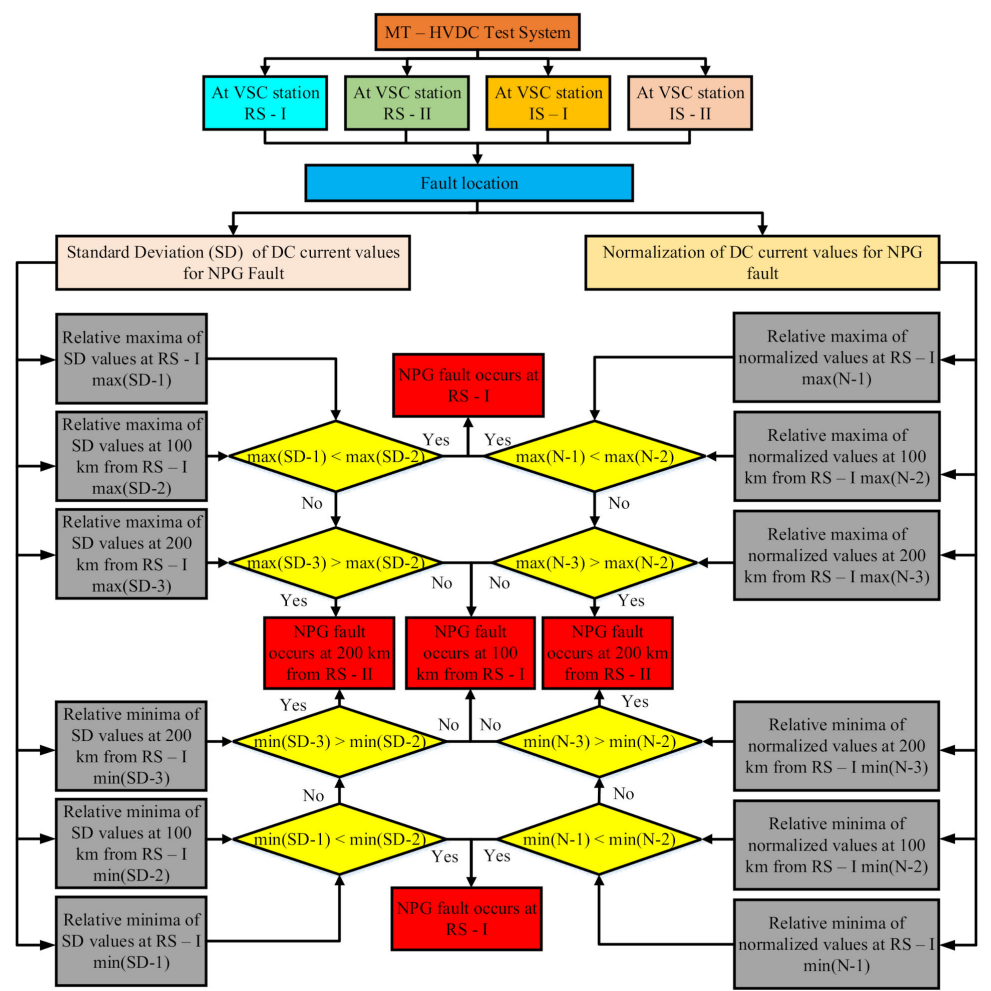

Figure 7. An algorithm for NPG fault location finding based on SVM, using supported features of standard deviation and normalization of DC current. 


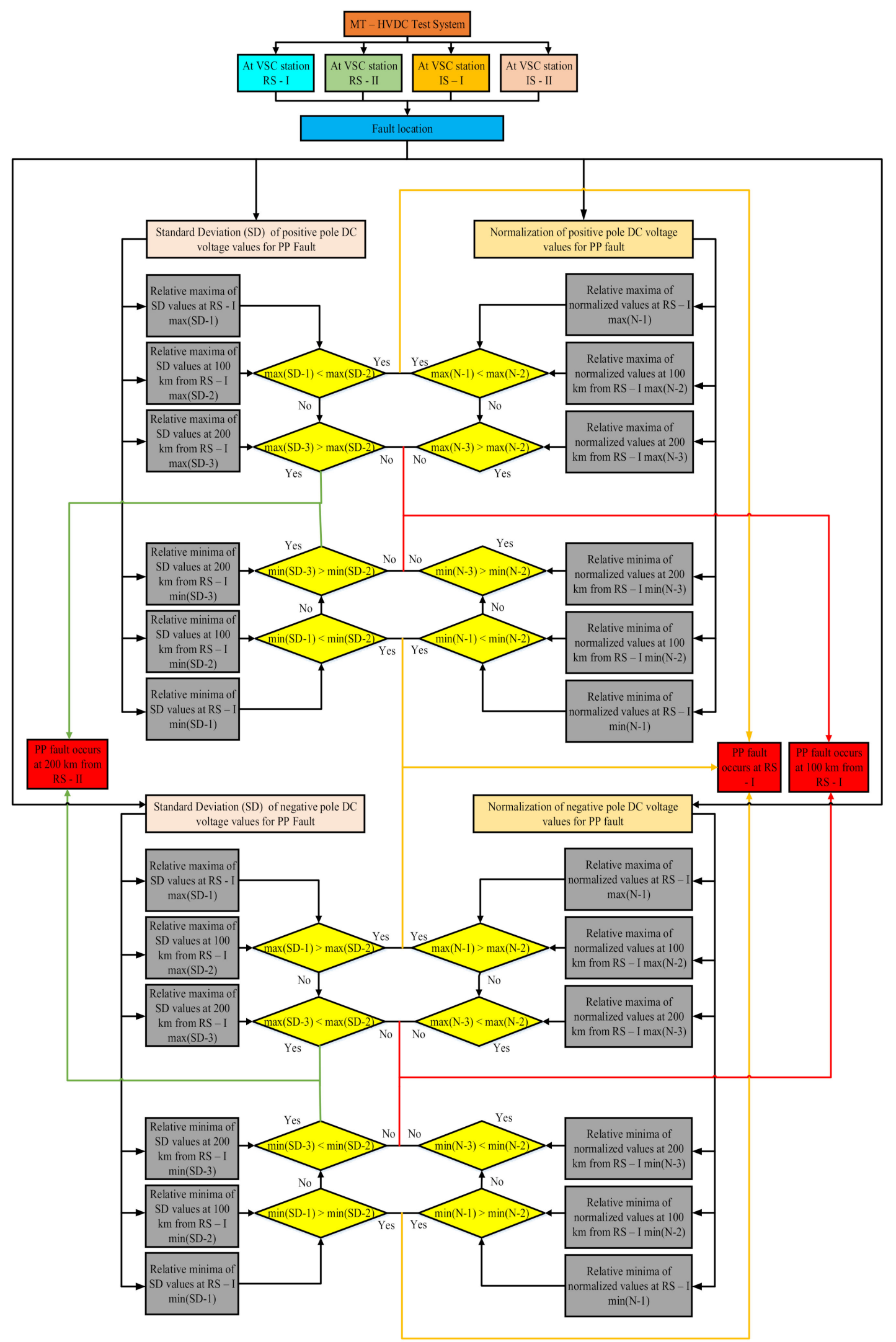

Figure 8. An algorithm for pole-to-pole (PP) fault location finding based on SVM, using supported features of standard deviation and normalization of DC voltage. 


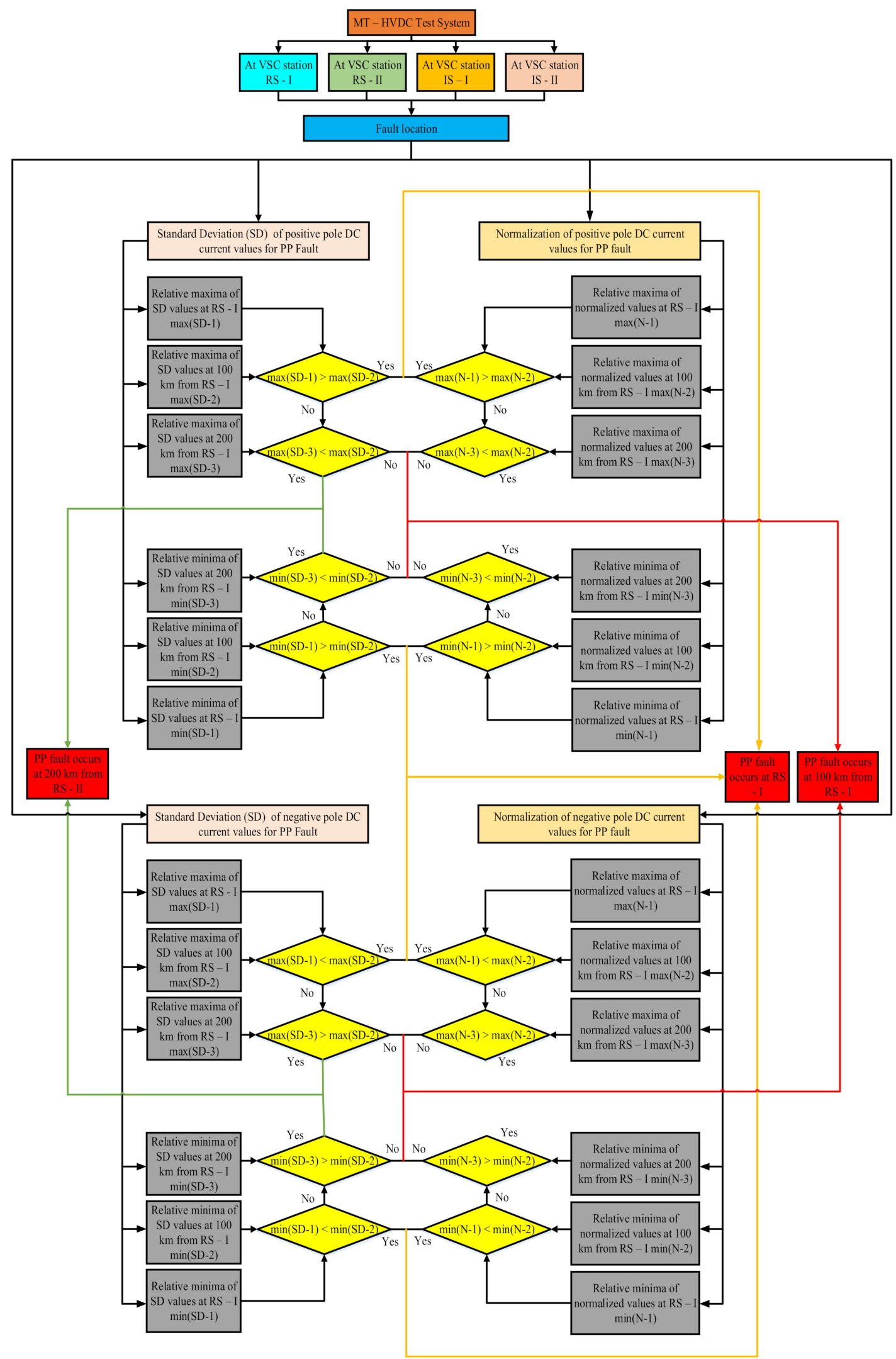

Figure 9. An algorithm for PP fault location finding based on SVM, using supported features of standard deviation and normalization of DC current. 
DC voltages and currents are measured at the positive pole in the case of PPG fault. Maximum and minimum values of SD and N, extracted from DC voltage, increase with the increase in the distance between the sensing terminal and fault point, as shown in Figure 4. Maximum and minimum values of $\mathrm{SD}$ and N, extracted from DC current, increase with the decrease in the distance between the sensing terminal and fault point, as presented in Figure 5.

In NPG fault, measurements of DC voltage and current are taken at the negative pole. SD and $\mathrm{N}$ are the features extracted from the measurements. Maximum and minimum values of $\mathrm{SD}$ and $\mathrm{N}$, extracted from DC voltage, decrease with the increase in the distance between the converter station and DC fault location, as presented in Figure 6. In the case of supported features derived from DC current measurements, maximum and minimum values of SD and $\mathrm{N}$ increase with the increase in the distance between VSC and fault point, as depicted in Figure 7.

In the case of PP fault, DC voltage and DC currents are measured at both positive and negative poles simultaneously. SD and $\mathrm{N}$ are the features extracted from pole measurements. In the condition of DC voltage measurements, maximum and minimum values of SD and N increase with the increase in the distance between relay position and fault location for positive pole. The maximum and minimum values of SD and N decrease with the increase in the distance between VSC and fault point for negative pole as depicted in Figure 8. In the condition of measurement of DC current, the decrease in the maximum and minimum values of $\mathrm{SD}$ and $\mathrm{N}$ with the increase in the distance between sensing terminal and fault location is found for positive pole. The increase in the maximum, and minimum values of SD and $\mathrm{N}$ with the increase in the distance between relay terminal and fault location is found for negative pole as presented in Figure 9.

\section{MT-HVDC Test System Understudy}

A single line diagram of the four-terminal HVDC system is shown in Figure 10. This test model consists of two offshore VSC stations, i.e., rectifier stations (RS-I and RS-II), and two onshore VSC stations, i.e., inverter stations (IS-I and IS-II). An average two-level VSCs value model is employed [56]. DC voltage droop and reactive power controls are applied to onshore VSC stations $[57,58]$. At offshore VSC stations, active power and AC voltage controls are used to ensure a constant power flow in the grid via AC voltage regulation [59]. The $d q$ control is applied at the primary level of the VSC stations [60].

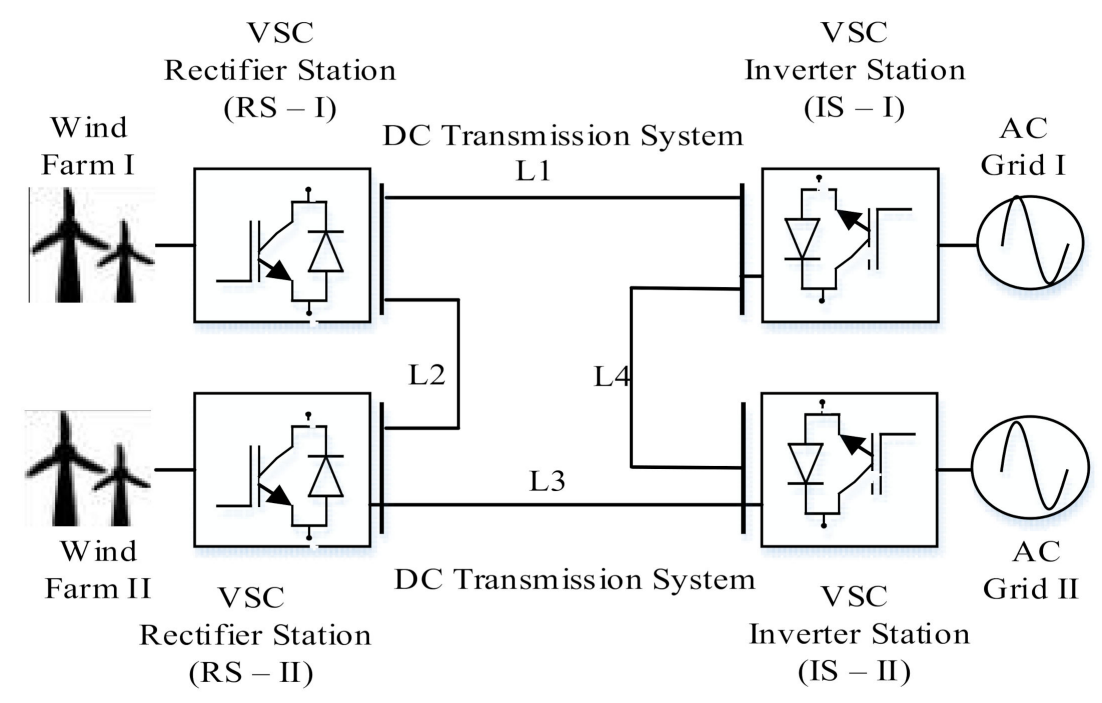

Figure 10. Multi-terminal high voltage direct current (MT-HVDC) test system.

In this bipolar HVDC transmission system, positive and negative DC voltages and DC currents are recorded for analysis. Four DC links designated as $L_{1}, L_{2}, L_{3}$, and $L_{4}$ with lengths $300 \mathrm{~km}, 200 \mathrm{~km}$, $300 \mathrm{~km}$, and $200 \mathrm{~km}$, respectively. 


\section{Simulations and Discussion}

The four-terminal HVDC test system of Figure 10 is developed in Matlab/Simulink to analyze the proposed protection algorithm. The parameters of the test system are given in Table A1 of Appendix A.

As the prime objective of this research is to identify, locate, and classify the faults in the MT-HVDC system. Therefore, three types of DC faults are studied on the four-terminal HVDC test system. These faults are positive pole to ground (PPG) fault, negative pole to ground (NPG) fault, and pole to pole (PP) fault, respectively.

The DC faults are considered cancer for MT-HVDC systems as the rapid building of DC fault current results in the DC-grid collapse. Faults can be established at different locations within the MT-HVDC grid and thus designated as different cases shown in Table 1.

Table 1. Different case of MT-HVDC test system.

\begin{tabular}{|c|c|c|}
\hline Scenarios & Location of Fault & Fault Type \\
\hline 1 & $\begin{array}{c}\text { RS-I } \\
\text { RS-II } \\
\text { IS-I } \\
\text { IS-II }\end{array}$ & No-fault \\
\hline 2 & $\begin{array}{c}\text { RS-I } \\
\text { RS-II } \\
\text { IS-I } \\
\text { IS-II }\end{array}$ & $\begin{array}{l}\text { PPG fault } \\
\text { NPG fault } \\
\text { PP fault }\end{array}$ \\
\hline 3 & $100 \mathrm{~km}$ at $L_{1}$ from RS-I & $\begin{array}{l}\text { PPG fault } \\
\text { NPG fault } \\
\text { PP fault }\end{array}$ \\
\hline 4 & $200 \mathrm{~km}$ at $L_{1}$ from RS-I & $\begin{array}{l}\text { PPG fault } \\
\text { NPG fault } \\
\text { PP fault }\end{array}$ \\
\hline 5 & $100 \mathrm{~km}$ at $L_{2}$ from RS-I & $\begin{array}{l}\text { PPG fault } \\
\text { NPG fault } \\
\text { PP fault }\end{array}$ \\
\hline 6 & $200 \mathrm{~km}$ at $L_{2}$ from RS-I & $\begin{array}{l}\text { PPG fault } \\
\text { NPG fault } \\
\text { PP fault }\end{array}$ \\
\hline 7 & $100 \mathrm{~km}$ at $L_{3}$ from RS-II & $\begin{array}{l}\text { PPG fault } \\
\text { NPG fault } \\
\text { PP fault }\end{array}$ \\
\hline 8 & $200 \mathrm{~km}$ at $L_{3}$ from RS-II & $\begin{array}{l}\text { PPG fault } \\
\text { NPG fault } \\
\text { PP fault }\end{array}$ \\
\hline 9 & $100 \mathrm{~km}$ at $L_{4}$ from RS-II & $\begin{array}{l}\text { PPG fault } \\
\text { NPG fault } \\
\text { PP fault }\end{array}$ \\
\hline 10 & $200 \mathrm{~km}$ at $L_{4}$ from RS-II & $\begin{array}{l}\text { PPG fault } \\
\text { NPG fault } \\
\text { PP fault }\end{array}$ \\
\hline
\end{tabular}

\subsection{Voltage and DC Current Analysis}

Voltage analysis is conducted to shape a theory that any electrical or mechanical change in the MT-HVDC system can be studied through DC voltages.

Similarly, the current is considered the primary measuring component in the MT-HVDC system as DC fault current rises rapidly. Thus, without DC current observations, it is impossible to decide or deploy protective equipment for expensive converter stations. 
Therefore, DC voltages and currents are measured at all VSC stations (RS-I, RS-II, IS-I, IS-II), as explained in Figure 11.

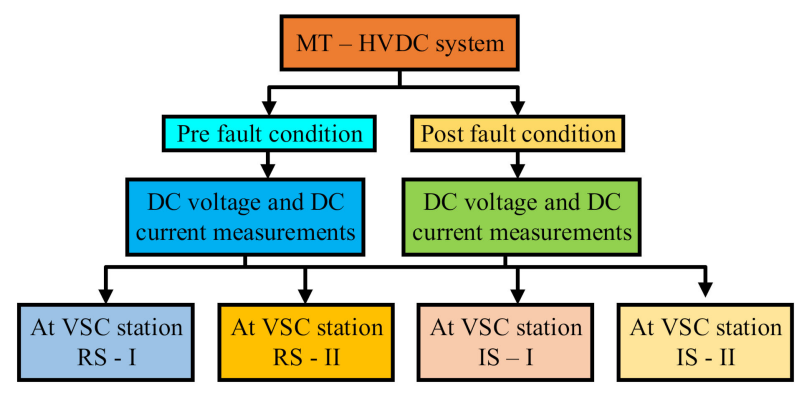

Figure 11. Pre-fault and post-fault measurements at VSC stations of the HVDC test system under study.

Table 1 provides detail of various scenarios studied under DC voltage and current analysis. Considering the length of the paper, only four cases are discussed comprehensively. And note that throughout the manuscript within Figures, blue lines are for positive pole profiles while red lines indicate negative pole characteristics.

\subsubsection{Scenario 1: No-Fault}

Under the no-fault case, DC voltages are measured at all four VSC stations, i.e., RS-I, IS-I, RS-II, and IS-II. Under normal conditions, DC voltage reaches a rated DC-link voltage, i.e., $100 \mathrm{kV}(1 \mathrm{pu})$ in less than $0.15 \mathrm{~ms}$. Thus, $1 \mathrm{pu}$ is considered a steady-state. It is found from the analysis that the transient behavior will exist in the system unless there is a charging of DC capacitors and the functioning of DC filters. Variation of DC voltages and decaying down of transients are shown in Figure 12 at all four VSCs.
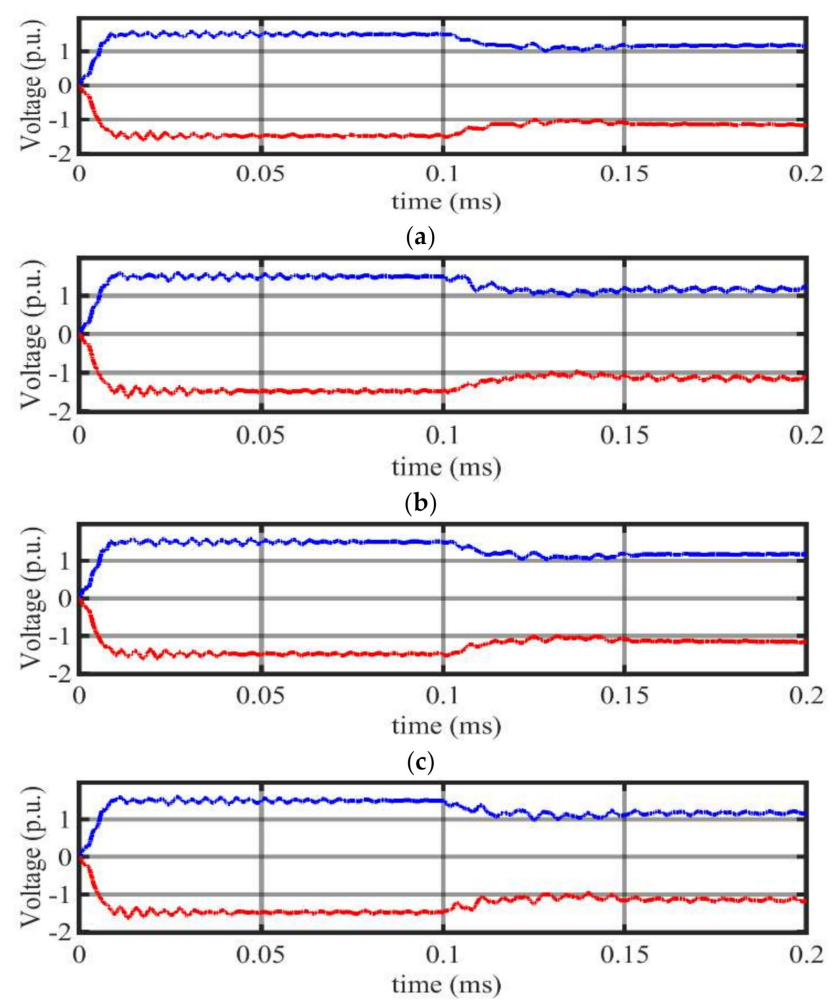

(d)

Figure 12. DC voltages measured at (a) RS-I, (b) IS-I, (c) RS-II, and (d) IS-II under normal condition. 
In the no-fault scenario, DC currents are also measured at all VSCs, i.e., RS-I, IS-I, RS-II, and IS-II, respectively, as shown in Figure 13. Transients decayed down in less than $0.15 \mathrm{~ms}$ and thus attained steady-state. The DC currents are reduced to zero at VSC stations. The protection scheme for no-fault state identification in the MT-HVDC system is proposed in Figure 14.

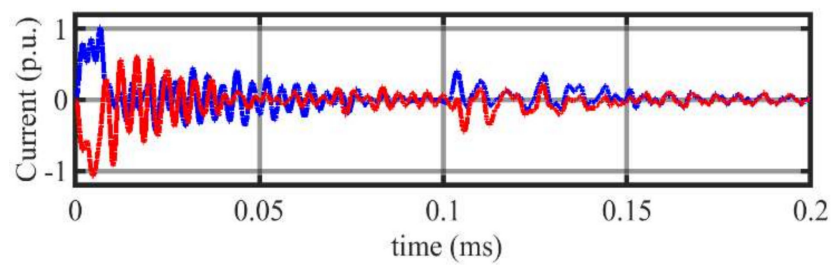

(a)

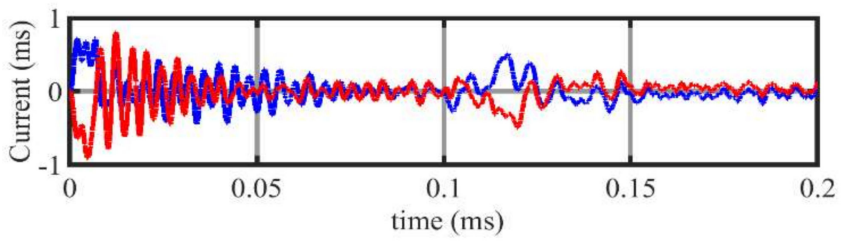

(b)

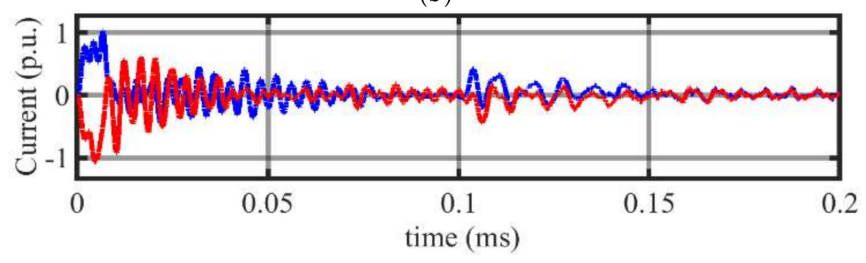

(c)

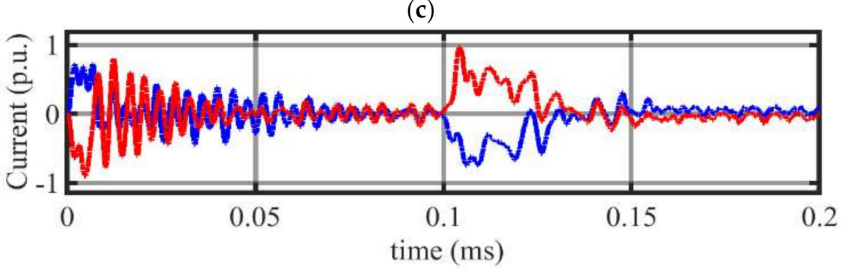

(d)

Figure 13. DC currents measured at (a) RS-I, (b) IS-I, (c) RS-II, and (d) IS-II under normal condition.

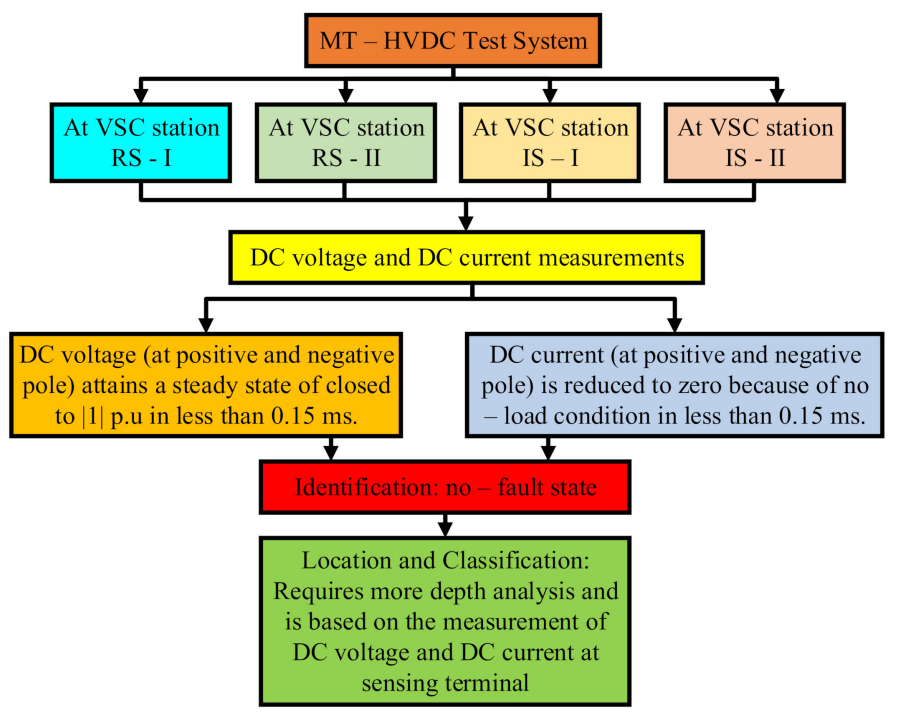

Figure 14. No-fault identification scheme in the MT-HVDC system. 


\subsubsection{Scenario 2: DC Fault at RS-I}

In this scenario, three types of DC fault events are developed at RS-I (VSC station). Fault events are PPG, NPG, and PP fault. DC voltages and currents are observed at all four VSC stations.

It is found from the simulations that in the event of PPG fault, positive DC voltages are reduced to zero with few immediate rising-immediate falling (IRIF) interruptions, as depicted in Figure 15a. This observation leads to locate the fault. On the other hand, voltages are seen increasing in the negative pole, almost two times the magnitude of voltages observed under the no-fault condition. This information provides a clear identification of PPG fault.
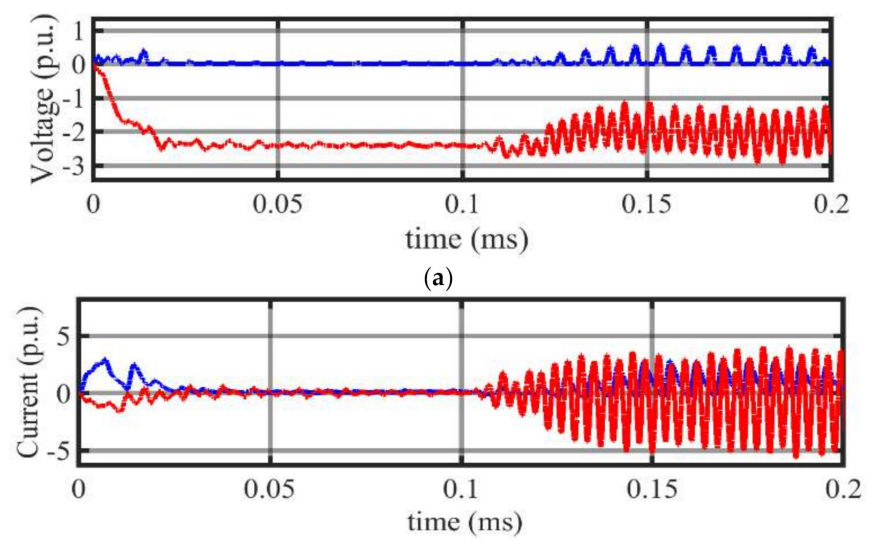

(b)

Figure 15. (a) DC voltage and (b) DC current at rectifier station (RS)-I PPG fault.

This DC voltage analysis is further supported by the DC current analysis, as shown in Figure 15b. It is observed from the simulations that the magnitude of initial transients develops in the PPG fault at the positive pole are approximately three to five times higher than those in no-fault condition.

Hence, dropping DC voltage to zero at the positive pole and high rise magnitudes of transients in DC currents is the main indication of identifying PPG fault. The protection scheme of identification of PPG fault is presented in Figure 16.

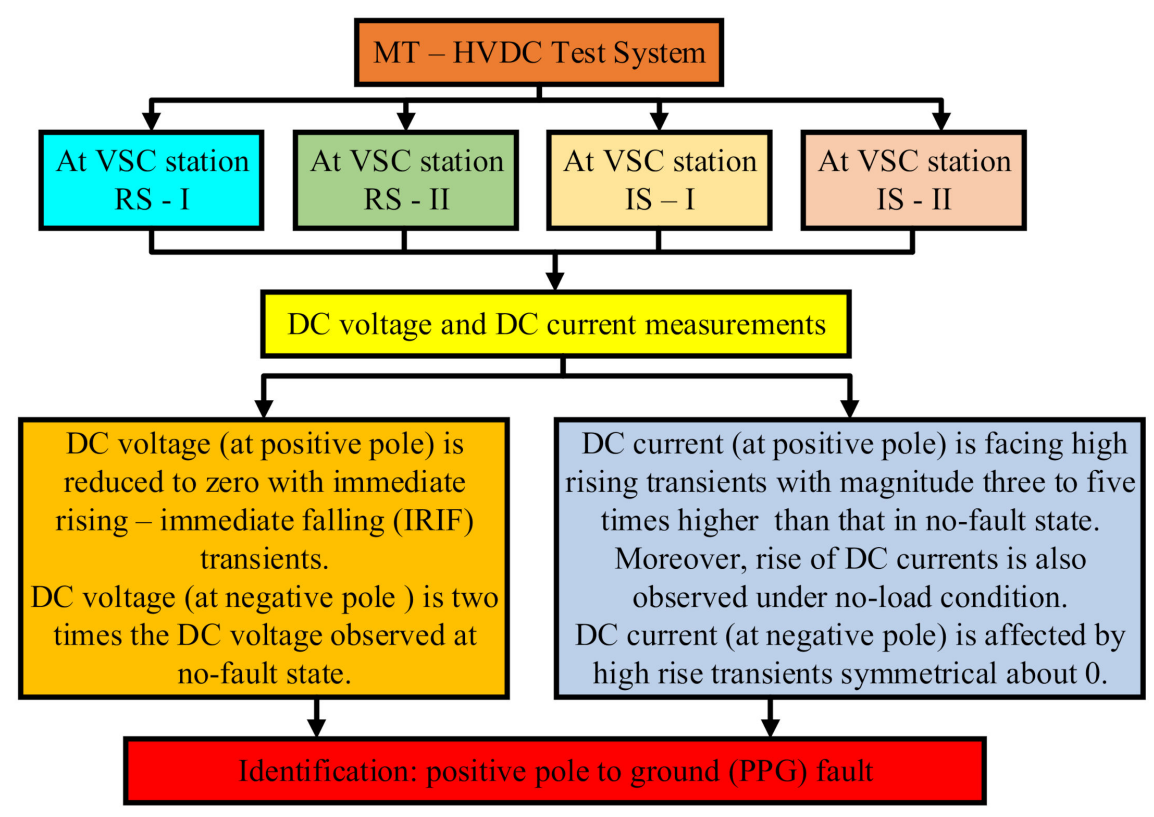

Figure 16. PPG fault identification scheme in the MT-HVDC test system. 
In the event of NPG fault, DC voltages start rising at the positive pole, as shown in Figure 17a, almost two times the magnitude of voltage observed under no-fault condition. On the other hand, DC voltages at the negative pole are reduced to zero with few IRIF interruptions. This information provides a clear identification of NPG fault.

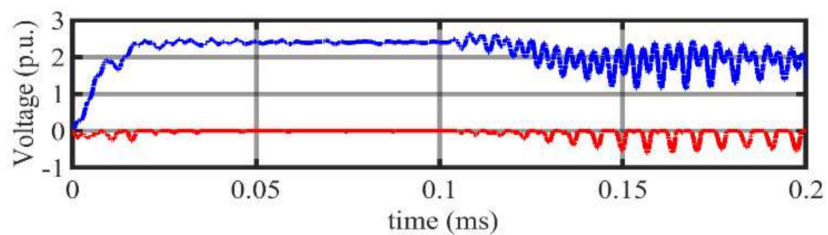

(a)

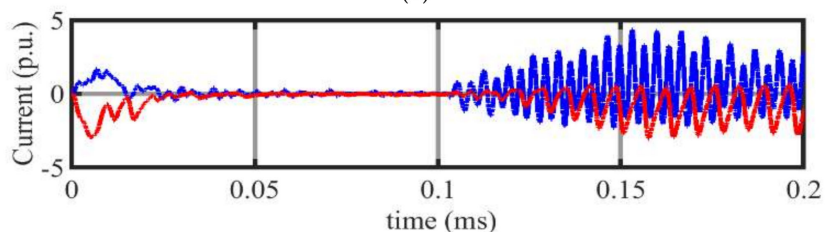

(b)

Figure 17. (a) DC Voltage and (b) DC current profiles at RS-I during NPG fault.

This DC voltage analysis is further backed by the current analysis, as shown in Figure $17 \mathrm{~b}$. It is observed from the simulations that the magnitude of the initial transients developed during NPG fault at the negative pole is approximately three to five times higher than that in a no-fault state.

Hence, the dropping of DC voltage closed to zero at the negative pole, and high rise magnitudes of transients in DC currents is the main indication of NPG fault identification. The protection scheme of identification of NPG fault is given in Figure 18.

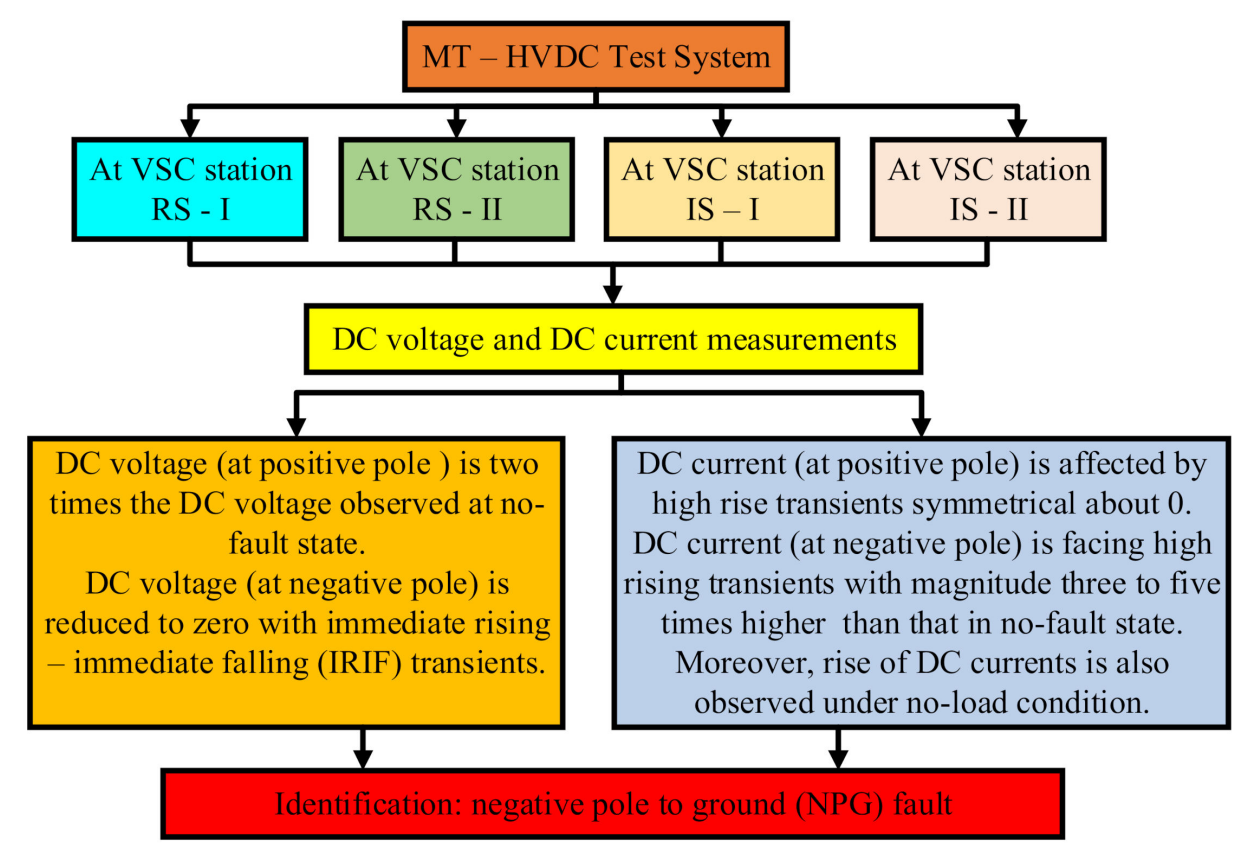

Figure 18. NPG fault identification scheme in the MT-HVDC test system.

Thirdly, PP fault is developed at RS-I. It is observed that the magnitude of DC voltages at both positive and negative poles are dropped down to $0.2 \mathrm{pu}$ as shown in Figure 19a. Transients developed during PP fault are stabilized in less than $0.15 \mathrm{~ms}$. 


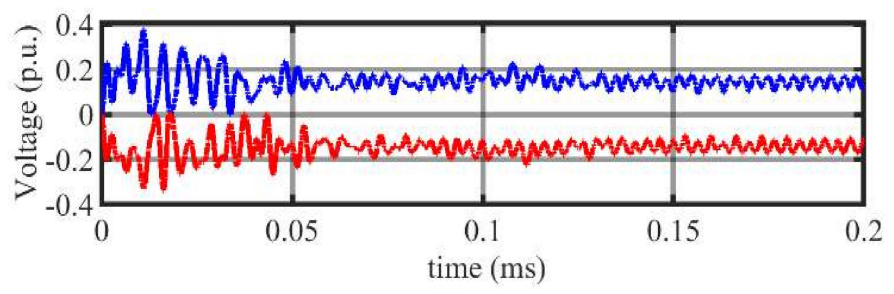

(a)

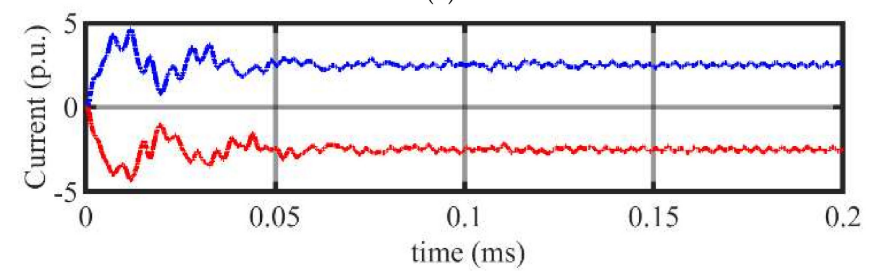

(b)

Figure 19. (a) DC voltage and (b) DC current profiles at RS-I during PP fault.

On the other hand, the initial rise in the DC fault current indicates a fault. It is found that the magnitude of transients during PP fault is increased to $3.0 \mathrm{pu}$ value, an indication of fault presence, as shown in Figure 19b.

Further, it is also observed that the offshore VSC stations follow the same characteristics, i.e., maintaining a DC current of 3 pu on both poles for $0.2 \mathrm{~ms}$. In contrast, current in onshore VSC stations decays to zero after developing high rise transients in less than $0.1 \mathrm{~ms}$ for IS-I and $0.025 \mathrm{~ms}$ for IS-II, respectively. This observation helps to determine the fault location in the case of PP fault. A protection scheme of identification of PP fault is shown in Figure 20.

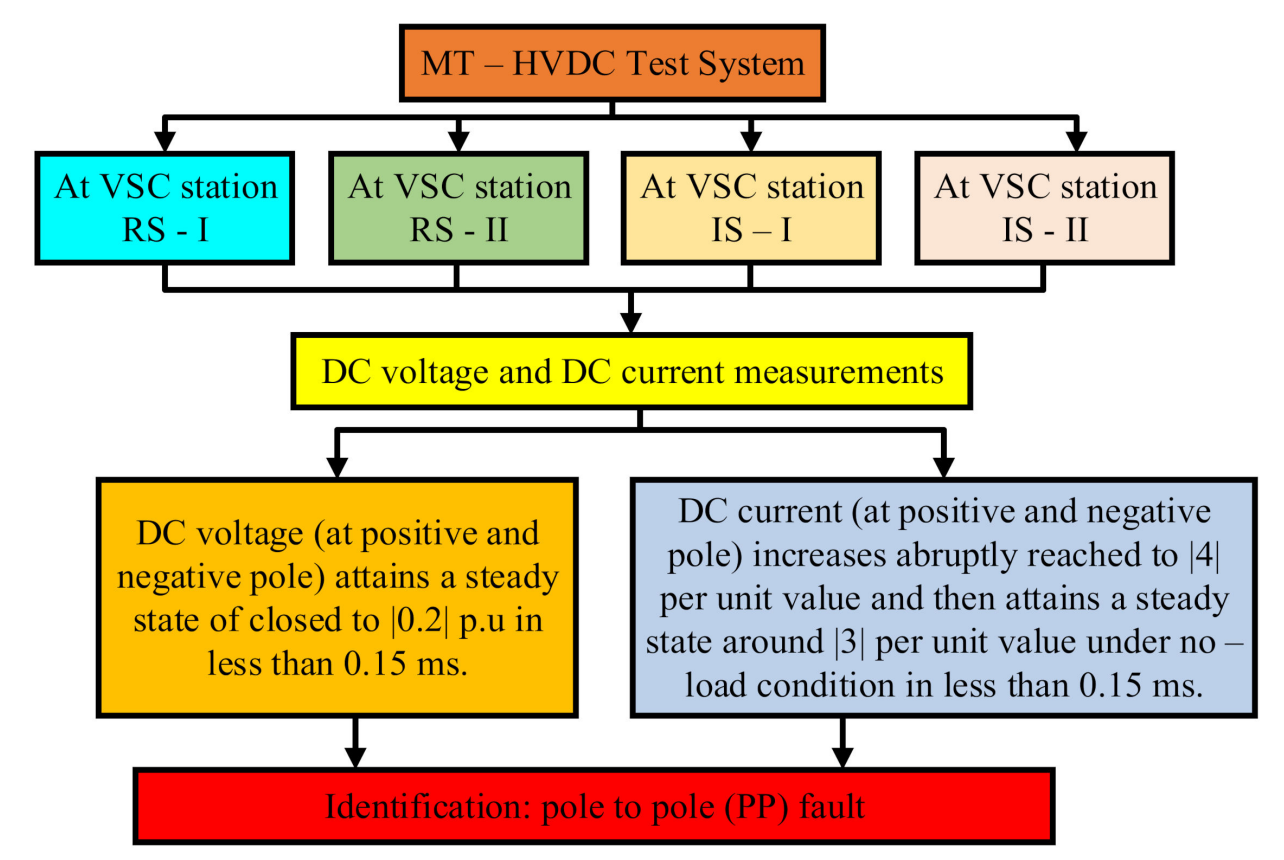

Figure 20. PP fault identification scheme in the MT-HVDC test system.

\subsubsection{Scenario 3: Fault at $100 \mathrm{~km}$ from RS-I at Line $\mathrm{L}_{1}$}

When a PPG fault occurs at $100 \mathrm{~km}$ from RS-I at line $L_{1}$, the rapid decay of DC voltage at the negative pole and rapid rise in DC current at the positive pole is observed in Figure 21a. The increase in the magnitude of the DC current at the positive pole is more noticeable compared to the rise in DC current at the negative pole. It is found from the simulations that the rising characteristics of the DC 
current under PPG fault at $100 \mathrm{~km}$ from RS-I are the same as the increasing characteristic observed at PPG fault at RS-I, as shown in Figure 21b. Therefore, more indepth analysis must be carried out, or more features must be explored to determine the exact location of the PPG fault.

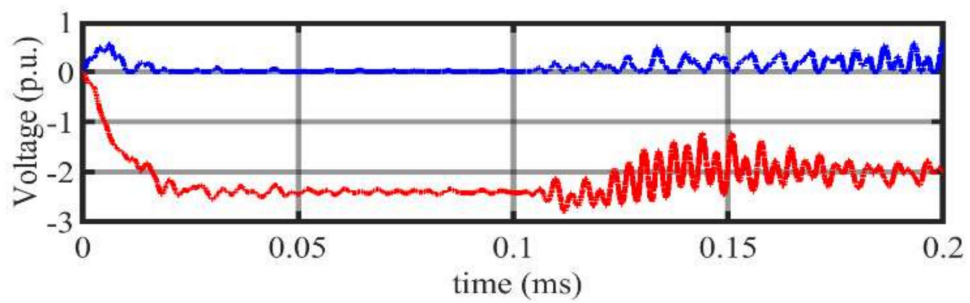

(a)

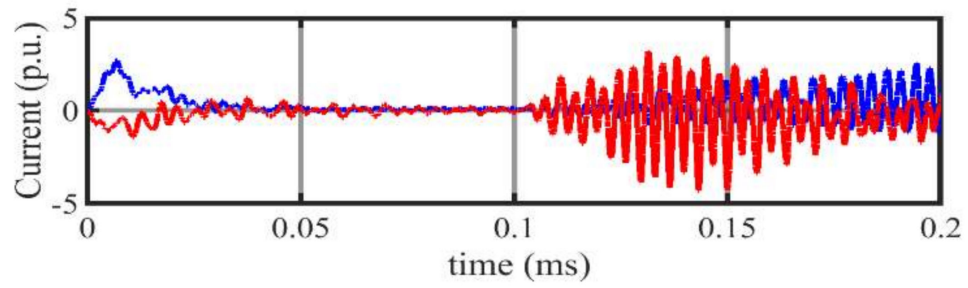

(b)

Figure 21. (a) DC Voltage and (b) DC current profiles under PPG fault occurred at $100 \mathrm{~km}$ from RS-I on Line 1.

Similarly, rapid decay in DC voltages at the negative pole and rapid rise of DC fault current at the negative pole is observed in the case of NPG fault at $100 \mathrm{~km}$ from RS-I at $L_{1}$ as depicted in Figure 22. This observation possesses a close resemblance to NPG fault at RS-I. Therefore, additional features are required to determine the exact location of the fault.

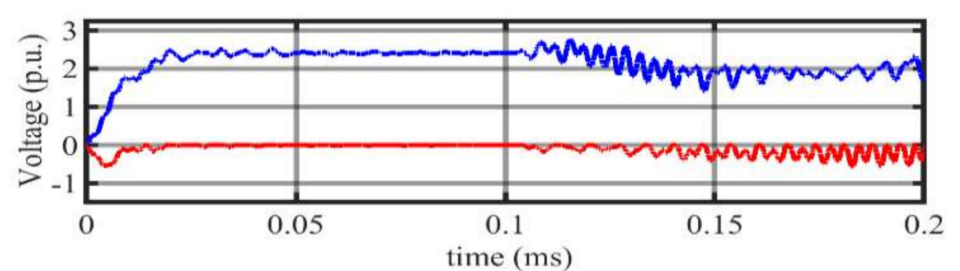

(a)

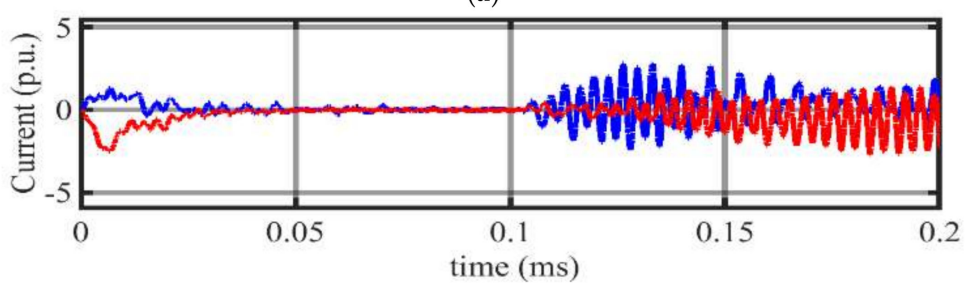

(b)

Figure 22. (a) DC Voltage and (b) DC current measured under NPG fault occurred at $100 \mathrm{~km}$ from RS-I on Line 1.

Lastly, Pole to pole fault event is created at $100 \mathrm{~km}$ from RS-I on line $L_{1}$. It is observed that both poles undergo variations in DC voltage and DC currents, as shown in Figure 23. DC voltages are reduced to a value of 0.2 p.u. It is much less than the value observed at the test system's no-fault state but similar to the value observed under PP fault at RS-I. The presence of transients in the DC voltages provokes in-depth analysis to determine the location of the fault. Similarly, the rise of DC currents at both poles is an identification of PP fault. The fault location is determined with the proposed SVM based algorithms, presented in Figures 8 and 9 . 


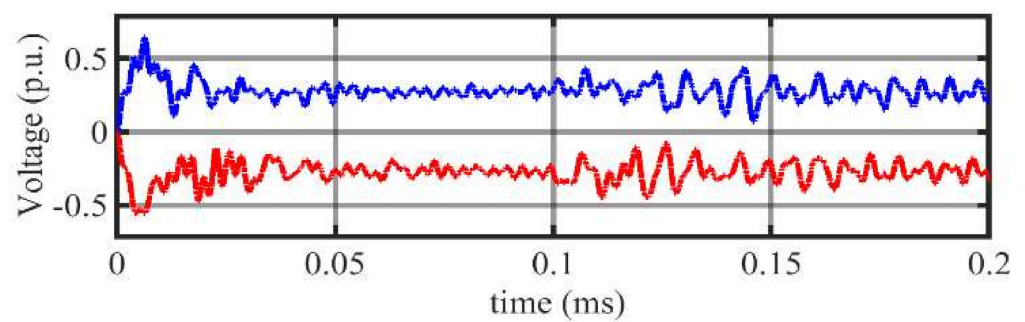

(a)

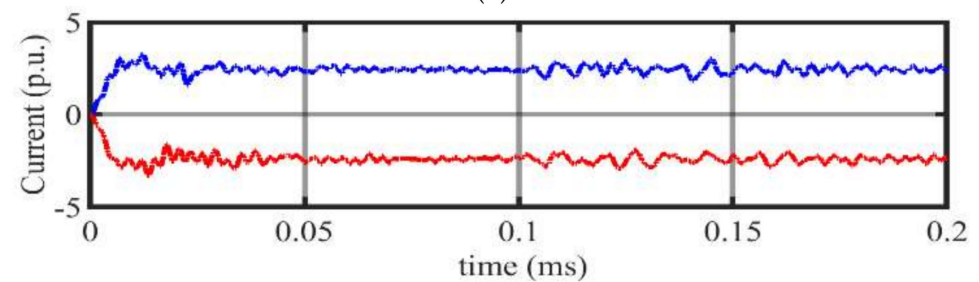

(b)

Figure 23. (a) DC Voltage and (b) DC current profiles under PP fault occurred at $100 \mathrm{~km}$ from RS-I on Line 1.

\subsubsection{Scenario 4: Fault at 200 Km From RS-I At Line $\mathrm{L}_{1}$}

Initially, the event of PPG fault is developed at $200 \mathrm{~km}$ from RS-I at line $L_{1}$. Reduction of DC voltage to 0 at positive pole and increase of DC voltage to two times the normal value of DC voltage, as shown in Figure 24a, is the representation of PPG fault according to the algorithm, presented in Figure 16. Because of fault in the positive line, positive pole current increases rapidly and then decays to zero, followed by high rise transients. On the other hand, transients in the DC current of the negative pole are symmetrical about the axis, as shown in Figure 24b.

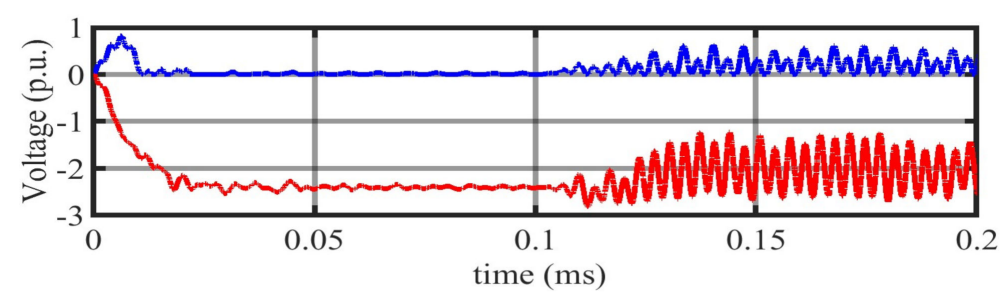

(a)

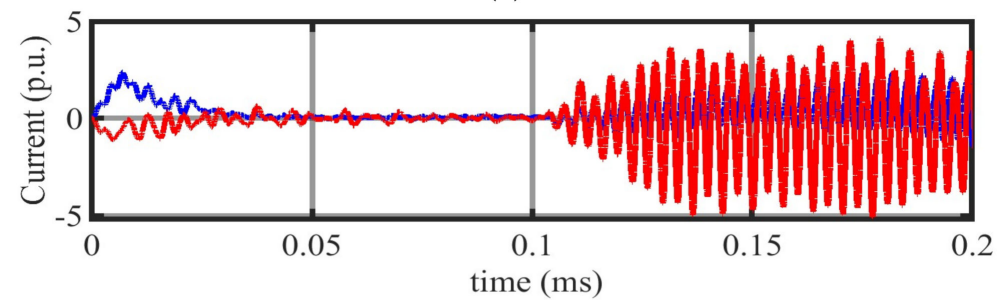

(b)

Figure 24. (a) DC Voltage and (b) DC current measured under PPG fault occurred 200 km from RS-I Line 1.

DC voltages are increased by two times the normal voltage at the positive pole in the case of NPG fault at $200 \mathrm{~km}$ from RS-I at line $L_{1}$ as shown in Figure 25a. The DC current at the negative pole undergoes a rapid increase in the time duration of $0.025 \mathrm{~ms}$, as shown in Figure 25b. Exploration of additional features is required to determine the exact location of the NPG fault. 


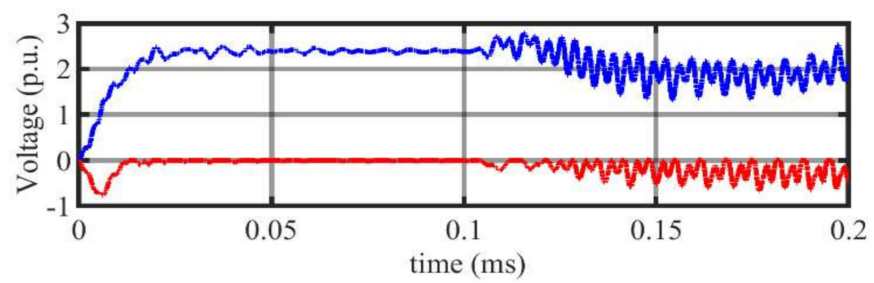

(a)

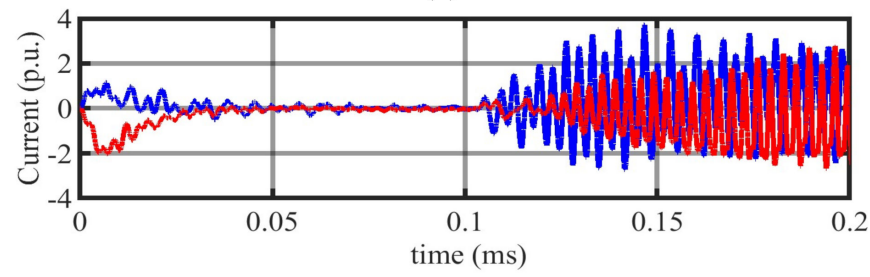

(b)

Figure 25. (a) DC Voltage and (b) DC current measured under NPG fault occurred $200 \mathrm{~km}$ from RS-I Line 1.

In the last, during PP fault, an abrupt rise in DC current and decay of DC voltage to 0.2 pu at both poles are noticed and are employed for identification, as shown in Figure 26. An in-depth study of transients present in DC voltages and DC currents is used to find the location of the fault in the MT-HVDC system.

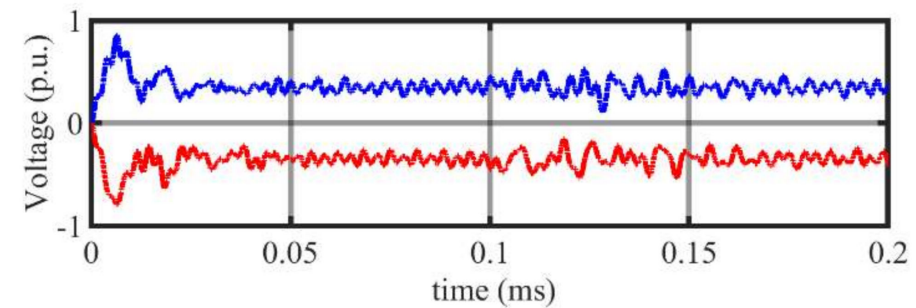

(a)

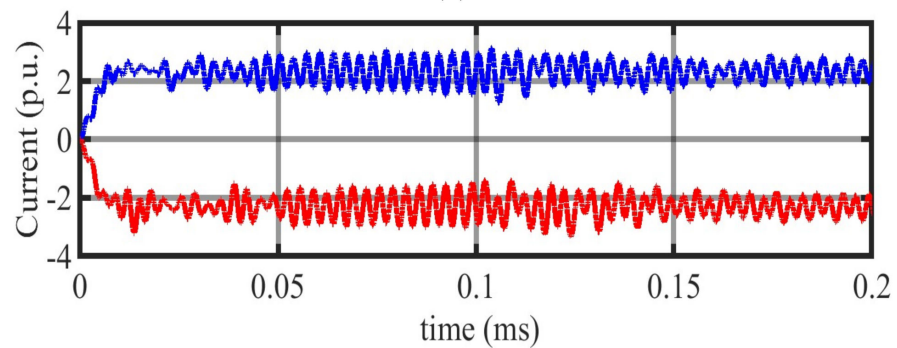

(b)

Figure 26. (a) DC Voltage and (b) DC current profiles under PP fault occurred at $200 \mathrm{~km}$ from RS-I Line 1.

As the protection of the MT-HVDC system cannot be completed without the classification of DC fault. Therefore, based on DC voltage and current values, the fault is classified in terms of PPG fault, NPG fault, and PP fault. The algorithms of fault classification based on DC voltage and current are presented in Figures 27 and 28, respectively. 


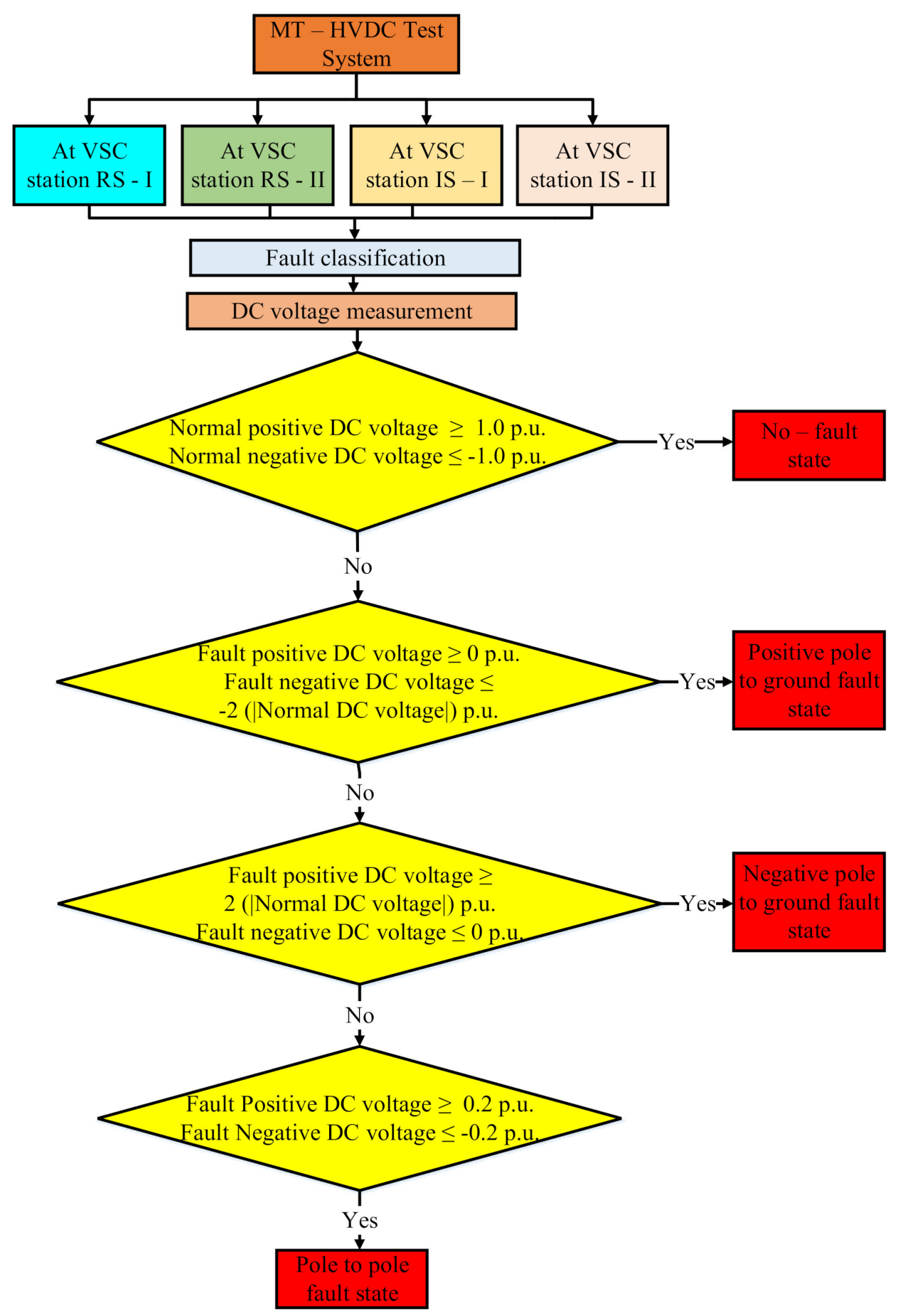

Figure 27. Fault classification scheme based on the DC voltage in the MT-HVDC test system. 


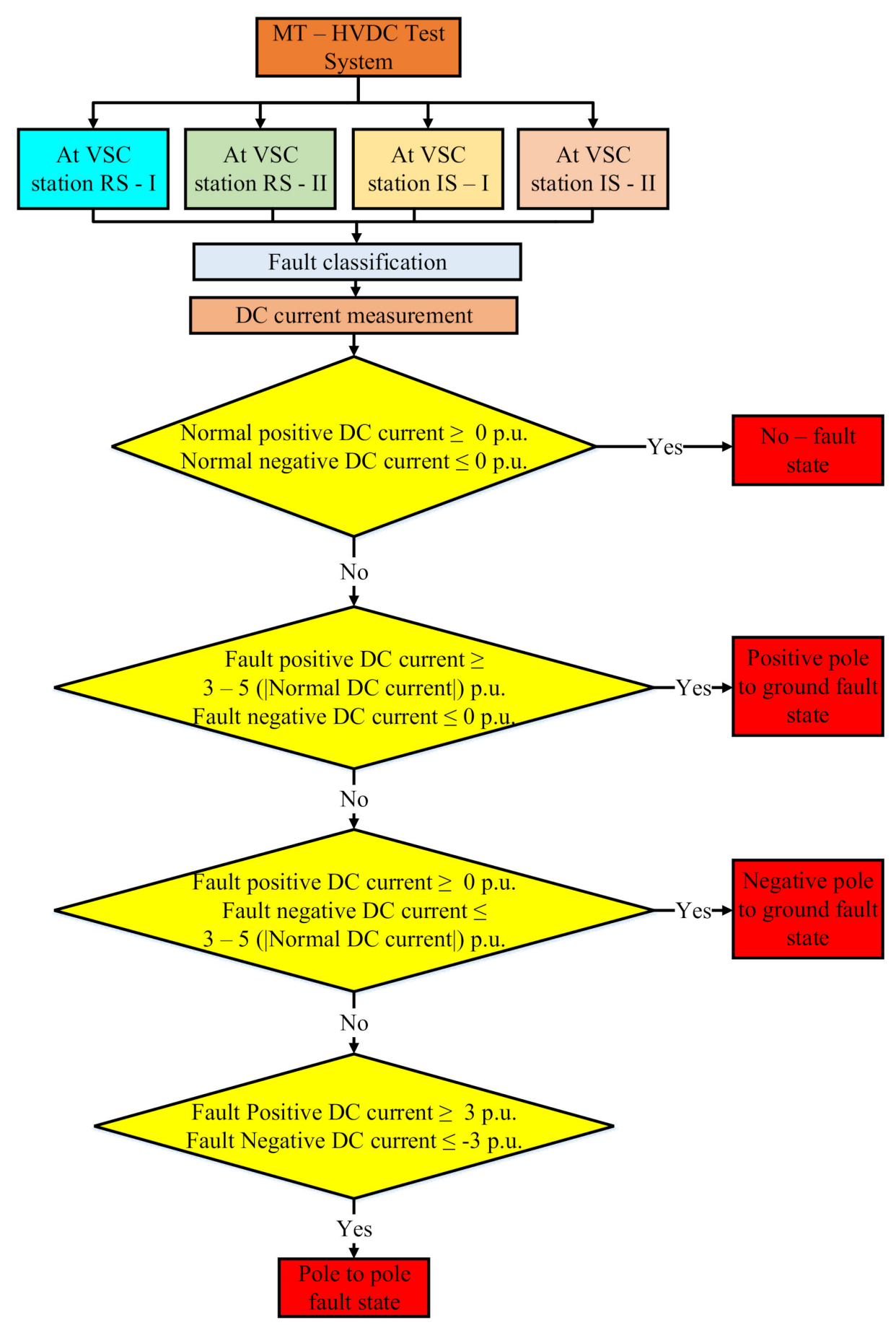

Figure 28. Fault classification scheme based on DC current in the MT-HVDC test system.

\subsection{SVM Algorithm for Fault Location}

It is found from the DC voltage and current analysis that faults in MT-HVDC are not only identified but can also be classified in terms of its types, i.e., PPG fault, NPG fault, and PP fault. However, the location of the fault requires more exploration of features of DC voltage and current.

In this research, a support vector machine (SVM) is applied to determine the location of the fault, and it proved from the simulations that SVM offers a precise determination of fault location in the presence of multi-dimensional data. This technique is memory efficient as SVM learning with short subsets of training data. 
In this test model, out of total $81,001 \times 17$ data values, a sample of $120 \times 4$ data values is used for training an SVM. Clear separation is achieved in multi-dimensional data by this proposed algorithm. Different cases are made, listed in Table 2, to demonstrate the performance of the proposed technique.

Table 2. Different cases for determination of fault location in the MT-HVDC test system.

\begin{tabular}{ccc}
\hline Scenarios & Training Data & Testing Data \\
\hline \multirow{3}{*}{ I } & & No-Fault Case \\
& & PPG Fault at RS-I \\
& & PPG Fault at $100 \mathrm{~km}$ from RS-I \\
& & PPG Fault at 200 km from RS-I \\
\cline { 3 - 3 } II & Positive Pole Voltage & No-Fault Case \\
& Negative Pole Voltage & NPG Fault at RS-I \\
& Positive Pole Current & NPG Fault at 100 km from RS-I \\
& Negative Pole Current & PPG Fault at 200 km from RS-I \\
\cline { 3 - 3 } & & No-Fault Case \\
& & PP Fault at RS-I \\
& & PP Fault at 100 km from RS-I \\
& & PP Fault at 200 km from RS-I \\
\hline
\end{tabular}

SVM is trained with the data of DC voltage and DC currents measured at RS-I. Data samples are taken between the time intervals of $1.4 \mathrm{~ms}$ to $3.4 \mathrm{~ms}$, as shown in Figure 29, to determine the location of the fault in this proposed test system.

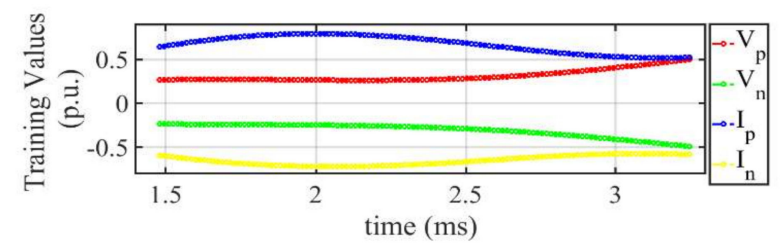

Figure 29. Training values for the SVM algorithm.

After successful training of the algorithm with 100\% accuracy, testing is conducted by applying different cases as described below.

\subsubsection{Scenario I}

In scenario-I, the trained SVM is tested with the data of DC voltage and current measured at RS-I to determine the location of PPG fault and no-fault cases, as shown in Figure 30. Piecewise changes for magnitude are observed in positive pole current $I_{p}$ and positive pole voltage $V_{p}$. These piecewise changes are employed to determine the location (the no-fault condition at RS-I, PPG fault at RS-I, PPG fault at $100 \mathrm{~km}$ from RS-I, PPG fault at $200 \mathrm{~km}$ from RS-I without errors). A similar procedure can also be adopted for the determination of PPG fault location in lines $L_{2}, L_{3}$ and $L_{4}$.

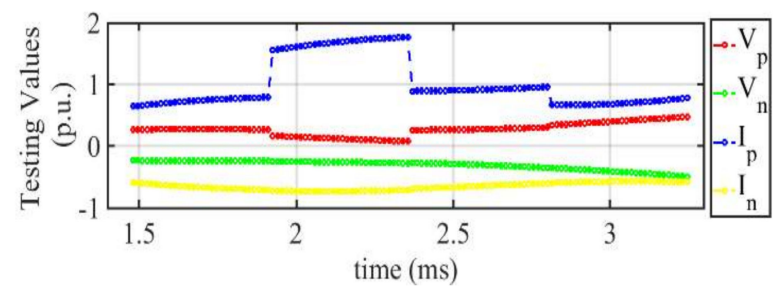

Figure 30. Testing values of the SVM algorithm under PPG fault. 
This classification technique is further supported with an analysis of standard deviation and normalization to demonstrate the realization of fault diagnosis through the proposed technique. It is interesting to note that the fault locations can easily be determined with simpler computations of relative maxima and minima of standard deviation and normalization. Therefore, dimensionality reduced data samples are employed for the determination of relative maxima and minima of standard deviation and normalization as shown in Figures 4 and 5.

\subsubsection{Scenario II}

In scenario II, the trained SVM is tested with the data of DC voltage and currents measured at RS-I to determine the location of NPG fault and no-fault cases, as shown in Figure 31. Piecewise changes are observed for negative pole current $I_{n}$ and negative pole voltage $V_{n}$. These piecewise changes are employed to determine fault location (a no-fault state at RS-I, NPG fault at RS-I, NPG fault at $100 \mathrm{~km}$ from RS-I, NPG fault at $200 \mathrm{~km}$ from RS-I without errors). A similar method can also be selected for the determination of NPG fault location in lines $L_{2}, L_{3}$, and $L_{4}$. SVM based fault location estimation for NPG fault is proposed in Figures 6 and 7.

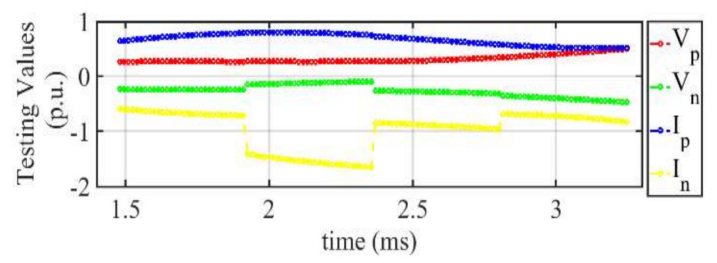

Figure 31. Testing values of the SVM algorithm under NPG fault.

\subsubsection{Scenario III}

In scenario III, the trained SVM is tested with the data of DC voltage and current measured at RS-I to determine the location of PP fault and no-fault cases, as shown in Figure 32. Piecewise changes for currents $I_{p}$ (positive pole current) and $I_{n}$ (negative pole current) and voltages $V_{p}$ (positive pole voltage) $V_{n}$ (negative pole voltage) are observed. These piecewise changes are employed to determine the location (a no-fault state at RS-I, PP fault at RS-I, PP fault at $100 \mathrm{~km}$ from RS-I, PP fault at $200 \mathrm{~km}$ from RS-I without errors). A similar approach can also be employed for the determination of PP fault location in lines $L_{2}, L_{3}$, and $L_{4}$. SVM based fault location estimation for PP fault is presented in Figures 8 and 9.

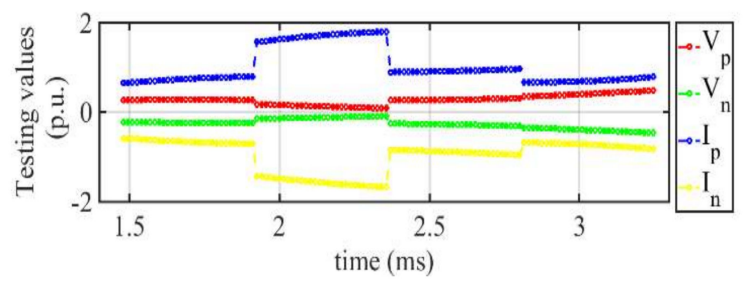

Figure 32. Testing values of the SVM algorithm under PP fault.

Table 3 presents the relative maxima and minima values of standard deviation and normalization based on DC voltage and current. These values are employed in the SVM algorithm for supporting the classification based on location in the test system. A reduced computational procedure with reduced featured data samples and a promising attribute with a diagnosis carried out in less than $0.15 \mathrm{~ms}$. Moreover, it provides an insight that this methodology of fault location can be extended to any number of VSCs for an MT-HVDC system, provokes its practical implementation. 
Table 3. Relative maxima and minima of standard deviation and normalized DC voltage and current values for fault location estimation.

\begin{tabular}{|c|c|c|c|c|c|}
\hline \multirow[t]{2}{*}{ Fault State } & \multirow[t]{2}{*}{ Parameters } & \multicolumn{2}{|c|}{ Standard Deviation (STD) Values } & \multicolumn{2}{|c|}{ Normalized Values } \\
\hline & & Maximum & Minimum & Maximum & Minimum \\
\hline \multirow{4}{*}{ No-Fault } & \multirow{4}{*}{$\begin{array}{l}\text { Positive Voltage } \\
\text { Negative Voltage } \\
\text { Positive Current }\end{array}$} & +2.75 & -0.80 & 0.50 & +0.26 \\
\hline & & +0.90 & -2.50 & -0.24 & -0.49 \\
\hline & & +1.20 & -1.65 & 0.79 & +0.52 \\
\hline & & +2.00 & -1.80 & -0.57 & -0.72 \\
\hline \multirow{2}{*}{ PPG Fault } & \multirow{6}{*}{$\begin{array}{l}\text { Positive Voltage } \\
\text { Positive Current }\end{array}$} & -0.90 & -1.80 & +0.16 & +0.08 \\
\hline & & +1.80 & +1.35 & +1.76 & +1.54 \\
\hline \multirow{2}{*}{ PPG Fault-100 km } & & +0.35 & -0.15 & +0.30 & +0.25 \\
\hline & & -0.15 & -0.25 & +0.95 & +0.89 \\
\hline \multirow{2}{*}{ PPG Fault-200 km } & & +2.00 & +0.70 & +0.47 & +0.33 \\
\hline & & -0.60 & -0.75 & +0.78 & +0.67 \\
\hline \multirow{2}{*}{ NPG Fault } & \multirow{6}{*}{$\begin{array}{l}\text { Negative Voltage } \\
\text { Negative Current }\end{array}$} & +1.60 & +1.10 & -0.03 & -0.09 \\
\hline & & -1.25 & -1.90 & -1.41 & -1.65 \\
\hline \multirow{2}{*}{ NPG Fault-100 km } & & 0.00 & -0.50 & -0.27 & -0.32 \\
\hline & & 0.00 & +0.35 & -0.84 & -0.96 \\
\hline \multirow[b]{2}{*}{ NPG Fault-200 km } & & -0.75 & -1.90 & -0.37 & -0.47 \\
\hline & & +0.40 & +0.75 & -0.70 & -0.83 \\
\hline \multirow{4}{*}{ PP Fault } & \multirow{12}{*}{$\begin{array}{l}\text { Positive Voltage } \\
\text { Negative Voltage } \\
\text { Positive Current }\end{array}$} & -0.90 & -1.80 & +0.16 & +0.08 \\
\hline & & +1.80 & +1.35 & +1.76 & +1.54 \\
\hline & & +1.60 & +1.10 & -0.03 & -0.09 \\
\hline & & -1.25 & -1.90 & -1.41 & -1.65 \\
\hline \multirow{4}{*}{ PP Fault-100 km } & & +0.35 & -0.15 & +0.30 & +0.25 \\
\hline & & -0.15 & -0.25 & +0.95 & +0.89 \\
\hline & & 0.00 & -0.50 & -0.27 & -0.32 \\
\hline & & 0.00 & +0.35 & -0.84 & -0.96 \\
\hline \multirow{4}{*}{ PP Fault-100 km } & & +2.00 & +0.70 & +0.47 & +0.33 \\
\hline & & -0.60 & -0.75 & +0.78 & +0.67 \\
\hline & & -0.75 & -1.90 & -0.37 & -0.47 \\
\hline & & +0.40 & +0.75 & -0.70 & -0.83 \\
\hline
\end{tabular}

Moreover, performance evaluation of the proposed algorithm for fault identification, classification, and the location is supported with the confusion matrix results, as shown in Figure 33. The trained algorithm is tested with true and predicted classes of data of different fault locations. Accuracy is proven because of the synchronism between true classes and predicted classes, as shown in Figure 33a. The fault's location is determined with a $100 \%$ true positive rate, and the predicted location is classified accurately, depicting the successful implementation within a period of $0.15 \mathrm{~ms}$, as shown in Figure 33b. The probability of predicting the positive value of fault location is 1, as shown in Figure 33c. Hence, the probability of discovering the false value of fault is zero, which depicts the excellent performance of the proposed technique for determining fault location in MT-HVDC systems.

\subsection{Proposed Structure of SVM-Based Protection Algorithem}

The applied structure of the proposed SVM-based protection technique is shown in Figure 34. DC voltage and currents are measured. PCA-based features are extracted from these measurements in order to reduce computational data and time. Relative maxima and minima of PCA-based features are evaluated and are fed into the trained SVM based model. This model-based relay identifies, classifies, and locates the fault and sends a trip signal to the corresponding breaker for fault current interruption. 


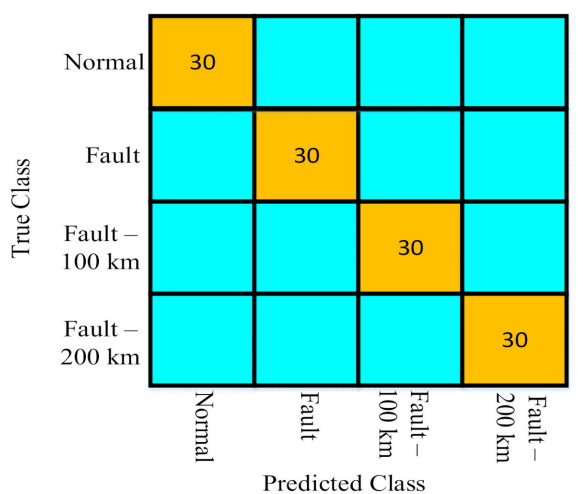

(a)

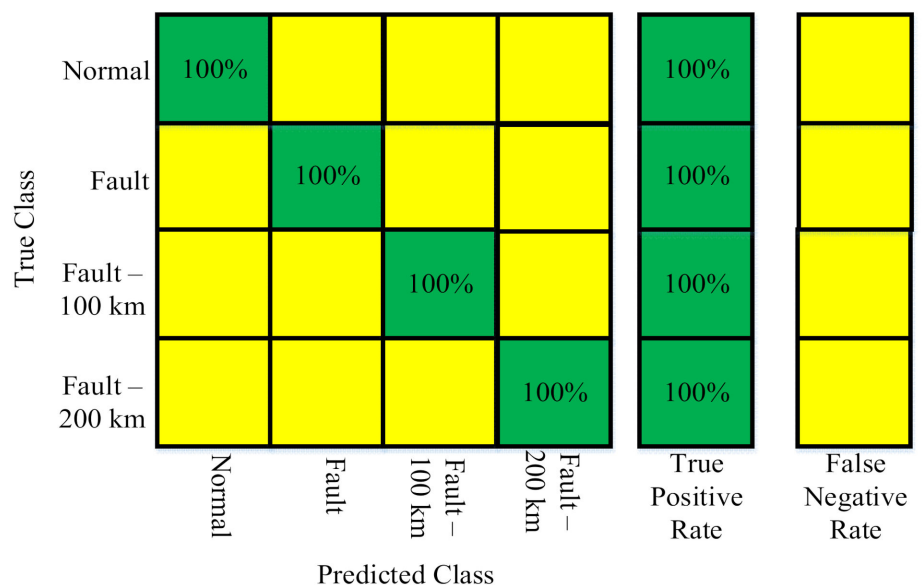

(b)
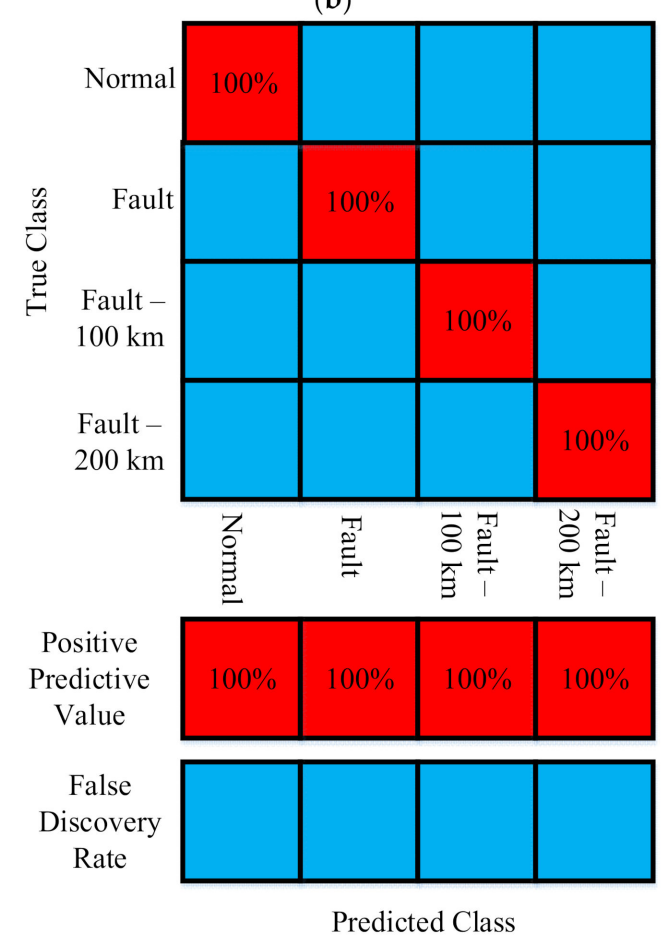

(c)

Figure 33. Confusion matrices based performance evaluation of the proposed technique for fault identification, classification, and location in MT-HVDC systems. 


\subsection{Performance Comparison of Protection Techniques}

Reduced computational time, accuracy, and realization with simpler calculations are the convincing features of this proposed SVM-based protection scheme. A detailed comparison of proposed protection techniques with different latest protection methods from literature is presented in Table 4.

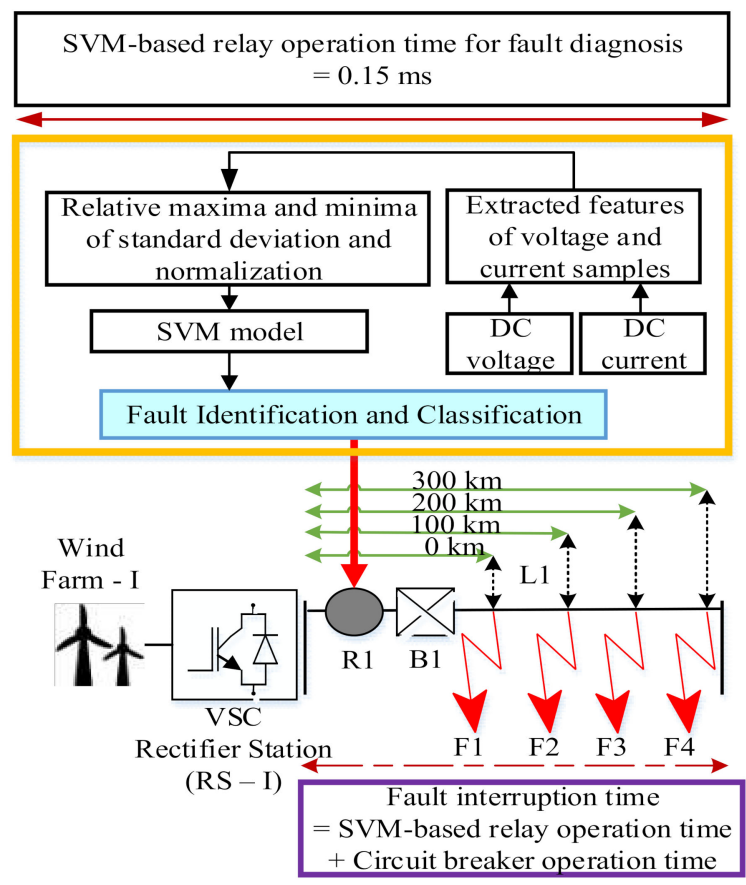

Figure 34. Applied structure of SVM-based protection technique.

Table 4. Comparison of different protection techniques for MT-HVDC systems.

\begin{tabular}{|c|c|c|c|}
\hline Parameters & $\begin{array}{l}\text { Proposed SVM } \\
\text { Technique }\end{array}$ & $\begin{array}{l}\text { Traditional SVM } \\
\text { Technique }\end{array}$ & Traveling Waves Technique \\
\hline $\begin{array}{l}\text { Arrival time } \\
\text { measurement }\end{array}$ & Not required & Not required & $\begin{array}{l}\text { Required. It is affected by } \\
\text { parameters of the transmission } \\
\text { line }\end{array}$ \\
\hline $\begin{array}{l}\text { Faults Near or at } \\
\text { Converter Stations }\end{array}$ & $\begin{array}{l}\text { Readily identified } \\
\text { and classified }\end{array}$ & $\begin{array}{l}\text { Not yet proven. } \\
\text { Additional features will } \\
\text { be required to train so } \\
\text { that fault near or at the } \\
\text { converter station could } \\
\text { be identified and } \\
\text { classified. }\end{array}$ & $\begin{array}{l}\text { Not Applicable. Additional } \\
\text { transformations like Fourier and } \\
\text { Wavelet Transform will be } \\
\text { required. }\end{array}$ \\
\hline Computational time & $\begin{array}{l}\text { Rapidly identified } \\
\text { and classified within } \\
0.15 \mathrm{~ms}\end{array}$ & $\begin{array}{l}0.3 \mathrm{~s} \text { will be required to } \\
\text { identify and classify. }\end{array}$ & $\begin{array}{l}\text { Complex computations increase } \\
\text { computational time. Moreover, } \\
\text { synchronization is required in } \\
\text { two-terminal methods. }\end{array}$ \\
\hline Response Time & $\sim 0.05 \mathrm{~ms}$ & Closed to $1 \mathrm{~ms}$ & $\begin{array}{l}\text { Few ms are required to respond } \\
\text { to abnormal conditions }\end{array}$ \\
\hline $\begin{array}{l}\text { Length of the time } \\
\text { window }\end{array}$ & $\begin{array}{l}\text { Length of } 0.2 \mathrm{~ms} \text { time } \\
\text { window is enough } \\
\text { for fault } \\
\text { identification and } \\
\text { classification }\end{array}$ & $\begin{array}{l}\text { A length of } 0.3 \mathrm{~s} \text { time } \\
\text { window is required. }\end{array}$ & $\begin{array}{l}\text { It varies and depends upon the } \\
\text { detection of the first traveling } \\
\text { wave-head. }\end{array}$ \\
\hline
\end{tabular}


Table 4. Cont.

\begin{tabular}{|c|c|c|c|}
\hline Parameters & $\begin{array}{l}\text { Proposed SVM } \\
\text { Technique }\end{array}$ & $\begin{array}{l}\text { Traditional SVM } \\
\text { Technique }\end{array}$ & Traveling Waves Technique \\
\hline Accuracy & $\begin{array}{l}\text { Accuracy is higher } \\
\text { and closed to } 100 \\
\text { percent in all types of } \\
\text { DC faults. }\end{array}$ & $\begin{array}{l}\text { Accuracy is higher in the } \\
\text { case of two-terminal } \\
\text { data, and accuracy is } \\
\text { compromised in the case } \\
\text { of single terminal data. }\end{array}$ & $\begin{array}{l}\text { Accuracy is greatly affected by } \\
\text { wave-speed, } \\
\text { non-synchronization, } \\
\text { and sampling frequency. }\end{array}$ \\
\hline Complexity & $\begin{array}{l}\text { Implementation is } \\
\text { easy. }\end{array}$ & Implementation is easy & $\begin{array}{l}\text { Complex digital processing } \\
\text { techniques and synchronization } \\
\text { (for two-terminal) is required. }\end{array}$ \\
\hline $\begin{array}{l}\text { Realization and } \\
\text { Practicality }\end{array}$ & $\begin{array}{l}\text { A simple analysis of } \\
\text { relative maxima and } \\
\text { minima of standard } \\
\text { deviation and } \\
\text { normalization is } \\
\text { done to prove its } \\
\text { realization. }\end{array}$ & $\begin{array}{l}\text { Error analysis is done to } \\
\text { prove its realization }\end{array}$ & $\begin{array}{l}\text { Traveling wave-based relays are } \\
\text { practically developed for } \\
\text { Brasada-Harney transmission } \\
\text { system and Bonneville Power } \\
\text { Administration's field. } \\
\text { Attenuation and dispersion are } \\
\text { the factors that change the } \\
\text { accuracy of finding fault } \\
\text { location. }\end{array}$ \\
\hline
\end{tabular}

\section{Additional Discussion and Achievements}

As previously explained in the Introduction section, DC grid protection's existing strategies and techniques are inaccurate, not robust, impose electrical noise, slow in response, complex calculations, and require expensive signal processing tools. This means that there exists not a single mature technique for the protection of HVDC systems. Moreover, it is possible to highlight the novel aspects of the proposed approach because it differs considerably from the solutions to be found in the existing literature. Firstly, this technique manages to diagnose the DC fault within a time frame of $0.15 \mathrm{~ms}$. To the best of the author's knowledge, this is the shortest time when the fault is diagnosed, as previous solutions offer comparatively large time for fault diagnosis. Secondly, this technique requires a simpler computations for relay operation. The magnitude of DC voltage and DC current and maxima and minima of standard deviation and normalization are the parameters employed for protective relaying. Indeed, a proposed technique offers reliable and rapid primary protection for DC grids. Thirdly, the proposed scheme utilizes relative maxima and minima values of standard deviation and normalization. This information is easier to understand and is aligned with the technical language of the protection system. Hence an understandable intuition from the human perspective regarding the decision-making process of protective relays is obtained. Fourthly, maxima and minima values of standard deviation also serve as a second step of fault identification and fault type-based classification on DC voltage and DC current values but serve as a first step in the case of fault location. This means that identification and classification are cross-checked in this proposed algorithm, which depicts its security and reliability. Moreover, confusion matrix-based prediction analysis proves its efficiency and enables the research to forecast fault conditions in MT-HVDC systems.

Finally, the feasibility of deploying the proposed fault diagnostic method to a real system is discussed. Computational complexity is reduced by the extraction of DC voltage and current based features. This characteristic reduces computational time, resulting in rapid training and testing of support vector machines. It can be concluded based on simulations that the proposed algorithm is perfectly suitable for real HVDC systems. Although this proposed algorithm involves capital cost for hardware development, software development, and data transformation, it can be viewed as a long term investment enabling reliability and successful integration of renewable energy. In short, it becomes profitable after a certain number of years because of the secure transfer of green energy. 


\section{Conclusions}

In this research, a support vector machine-based protection technique is proposed for MT-HVDC systems. Simulations are developed for a four-terminal HVDC system in Simulink/Matlab under the no-fault, pole to ground fault, and pole to pole fault conditions and at different locations. The proposed protection technique offers rapid fault identification, classification, and location within a timeframe of $0.15 \mathrm{~ms}$, enabling circuit breakers to respond accordingly. Computational complexities and training time of SVM for fault diagnosis are reduced by PCA based features. Therefore, building up large DC fault currents that could damage the MT-HVDC systems and expensive power electronic circuitries is evaded by quick fault diagnosis. Moreover, the robustness and abruptness of the proposed protection algorithm enhance the safety margins of VSC converters. Thus, fewer insulations are required for converter stations against the rapid rise of DC fault currents under abnormal conditions.

An applied demonstration of the proposed protection algorithm is carried out by the supportive analysis of relative maxima and minima of standard deviation and normalization. Confusion matrices confirm its realization with more straightforward computations.

Author Contributions: Conceptualization, R.M.; methodology, R.M.; software, R.M.; validation, R.M.; formal analysis, R.M.; investigation, R.M.; resources, R.M., A.R.; data curation, R.M.; writing-original draft preparation, R.M.; writing-review and editing, R.M. and A.R.; supervision, A.R.; project administration, A.R.; funding acquisition, R.M. All authors have read and agreed to the published version of the manuscript.

Funding: This research received no external funding.

Acknowledgments: The authors are thankful to the Department of Electrical Engineering, University of Lahore, Lahore, Pakistan, for providing facilities to conduct this research.

Conflicts of Interest: The authors declare no conflict of interest.

\section{Nomenclature}

$\begin{array}{ll}x_{i} & \text { Input vector } \\ d_{i} & \text { Class corresponding to the } i \text { th input vector. } \\ \xi & \text { Slack variable } \\ C & \text { User specified parameter } \\ \left\{x_{i}, d_{i}\right\}_{i=1}^{N} & \text { Training data set } \\ w & \text { Weight vector } \\ m_{0} & \text { Dimensions of input space } \\ m_{f} & \text { Dimensions of feature space } \\ \varphi(x) & \text { Point of transformed feature space } \\ \alpha_{i} & \text { Coefficients of the Lagrange multiplier } \\ K\left(x, x_{i}\right) & \text { Traditional Euclidean inner product of the input vector } x \text { with the support vector } x_{i} . \\ p & \text { Raw samples } \\ q & \text { Process variables } \\ \text { Cov } & \text { Covariance matrix } \\ a_{e} \text { and } a_{e} & \text { Projection vectors of } a \\ S_{0}, S_{1}, S_{2}, S_{3} & \text { Indicators } \\ L_{1}, L_{2}, L_{3} \text { and } L_{4} & \text { Line lengths } \\ d q & \text { Direct-quadrature } \\ V_{A C} & \text { AC Voltage } \\ V_{D C} & \text { DC Voltage } \\ \mathrm{AC} & \text { Alternating Current } \\ \mathrm{ANN} & \text { Artificial Neural Networks } \\ \mathrm{DC} & \text { Direct Current } \\ \mathrm{HVDC} & \text { High Voltage Direct Current } \\ \mathrm{IGBTs} & \text { Insulated Gate Bipolar Transistors } \\ \mathrm{IRIF} & \\ & \text { Immediate Rising-Immediate Falling } \\ & \end{array}$




$\begin{array}{ll}\text { IS-I and IS-II } & \text { Inverter Station I and Inverter Station II } \\ \text { ML } & \text { Machine Learning } \\ \text { MT-HVDC } & \text { Multi-terminal High Voltage Direct Current } \\ \text { N } & \text { Normalization } \\ \text { NPG } & \text { Negative Pole to Ground } \\ \text { PCA } & \text { Principal Component Analysis } \\ \text { PP } & \text { Pole to Pole } \\ \text { PPG } & \text { Positive Pole to Ground } \\ \text { Pu } & \text { Per Unit } \\ \text { R1 and B1 } & \text { Relay 1 and DC Breaker 1 } \\ \text { RS-I and RS-II } & \text { Rectifier Station I and Rectifier Station II } \\ \text { SD } & \text { Standard Deviation } \\ \text { SVM } & \text { Support Vector Machine } \\ \text { TW } & \text { Traveling Wave } \\ \text { VSCs } & \text { Voltage Source Converters }\end{array}$

\section{Appendix A}

The parameters of the test system are presented here.

Table A1. Parameters of the test system.

\begin{tabular}{|c|c|c|c|c|}
\hline Parameters & VSC-I & VSC-II & VSC-III & VSC-IV \\
\hline Function & Rectifier (RS-I) & Inverter (IS-I) & Rectifier (RS-II) & Inverter (IS-II) \\
\hline AC Voltage $(\mathrm{kV})$ & 230 & 230 & 230 & 230 \\
\hline DC Voltage $(\mathrm{kV})$ & 100 & 100 & 100 & 100 \\
\hline Transformer (MVA) & 200 & 200 & 200 & 200 \\
\hline AC Filters (MVAR) & 40 & 40 & 40 & 40 \\
\hline $\begin{array}{l}\text { Phase Reactor's } \\
\text { Resistance (Ohms) }\end{array}$ & 0.0075 & 0.0075 & 0.0075 & 0.0075 \\
\hline $\begin{array}{l}\text { Phase Reactor's } \\
\text { Inductance (mH) }\end{array}$ & 23.8 & 23.8 & 23.8 & 23.8 \\
\hline DC Capacitance $(\mu \mathrm{F})$ & 70 & 70 & 70 & 70 \\
\hline $\begin{array}{l}\text { 3rd Harmonic Filter } \\
\text { Capacitance }(\mu \mathrm{F})\end{array}$ & 12 & 12 & 12 & 12 \\
\hline $\begin{array}{l}\text { 3rd Harmonic Filter } \\
\text { Resistance (Ohms) }\end{array}$ & 0.15 & 0.15 & 0.15 & 0.15 \\
\hline $\begin{array}{l}\text { 3rd Harmonic Filter } \\
\text { Inductance }(\mathrm{mH})\end{array}$ & 47 & 47 & 47 & 47 \\
\hline $\begin{array}{l}\text { Smoothing Reactor's } \\
\text { Resistance (Ohms) }\end{array}$ & 0.025 & 0.025 & 0.025 & 0.025 \\
\hline $\begin{array}{l}\text { Smoothing Reactor's } \\
\text { Inductance }(\mathrm{mH})\end{array}$ & 8.0 & 8.0 & 8.0 & 8.0 \\
\hline $\begin{array}{l}\text { Power Electronic } \\
\text { Component }\end{array}$ & IGBTs & IGBTs & IGBTs & IGBTs \\
\hline
\end{tabular}

\section{References}

1. Van Hertem, D.; Ghandhari, M. Multi-terminal VSC HVDC for the European supergrid: Obstacles. Renew. Sustain. Energy Rev. 2010, 14, 3156-3163. [CrossRef]

2. Azizi, S.; Sanaye-Pasand, M.; Abedini, M.; Hassani, A. A traveling-wave-based methodology for wide-area fault location in multi-terminal DC systems. IEEE Trans. Power Deliv. 2014, 29, 2552-2560. [CrossRef]

3. Muzzammel, R. Restricted Boltzmann machines based fault estimation in multi terminal HVDC transmission system. In Intelligent Technologies and Applications. INTAP 2019, Communications in Computer and Information Science; Bajwa, I.S., Sibalija, T., Jawawi, D., Eds.; Springer: Singapore, 2020; Volume 1198, pp. 772-790.

4. Gomis-Bellmunt, O.; Liang, J.; Ekanayake, J.; King, R.; Jenkins, N. Topologies of multi-terminal HVDC-VSC transmission for large offshore wind farms. Electr. Power Syst. Res. 2011, 81, 271-281. [CrossRef] 
5. Yang, Q.; Le Blond, S.; Aggarwal, R.; Wang, Y.; Li, J. New ANN method for multi-terminal HVDC protection relaying. Electr. Power Syst. Res. 2017, 148, 192-201. [CrossRef]

6. Flourentzou, N.; Agelidis, V.G.; Demetriades, G.D. VSC-based HVDC power transmission systems: An overview. IEEE Trans. Power Electr. 2009, 24, 592-602. [CrossRef]

7. Sano, K.; Takasaki, M. A surgeless solid-state DC circuit breaker for voltage-source-converter-based HVDC systems. IEEE Trans. Ind. Appl. 2014, 50, 2690-2699. [CrossRef]

8. Das, S.; Santoso, S.; Gaikwad, A.; Patel, M. Impedance-based fault location in transmission networks: Theory and application. IEEE Access 2014, 2, 537-557. [CrossRef]

9. Agarwal, S.; Swetapadma, A.; Panigrahi, C.; Dasgupta, A. Fault analysis method of integrated high voltage direct current transmission lines for onshore wind farm. J. Mod. Power Syst. Clean Energy 2019, 7, 621-632. [CrossRef]

10. Daisy, M.; Dashti, R.; Shaker, H.R. A new fault-location method for HVDC transmission-line based on DC components of voltage and current under line parameter uncertainty. Electr. Eng. 2017, 99, 573-582. [CrossRef]

11. Luo, G.; Yao, C.; Liu, Y.; Tan, Y.; He, J.; Wang, K. Stacked auto-encoder based fault location in VSC-HVDC. IEEE Access 2018, 6, 33216-33224. [CrossRef]

12. Muzzammel, R.; Fateh, H.M.; Ali, Z. Analytical behaviour of thyrister based HVDC transmission lines under normal and faulty conditions. In Proceedings of the International Conference on Engineering and Emerging Technologies (ICEET), Lahore, Pakistan, 22-23 February 2018; IEEE: Lahore, Pakistan; pp. 1-5.

13. Naidoo, D.; Ijumba, N.M. HVDC Line protection for the proposed HVDC systems. In Proceedings of the International Conference on Power System Technology, Singapore, 21-24 November 2004; pp. 21-24.

14. Muzzammel, R.; Raza, A.; Hussain, M.R.; Abbas, G.; Ahmed, I.; Qayyum, M.; Rasool, M.A.; Khaleel, M.A. MT-HVdc systems fault classification and location methods based on traveling and non-traveling waves-A comprehensive review. Appl. Sci. 2019, 9, 4760. [CrossRef]

15. Muzzammel, R. Traveling waves-based method for fault estimation in HVDC transmission system. Energies 2019, 12, 3614. [CrossRef]

16. Wang, D.; Hou, M. Travelling wave fault location principle for hybrid multi-terminal LCC-VSC-HVDC transmission line based on R-ECT. Electr. Power Energy Syst. 2020, 117, 1-9. [CrossRef]

17. Pathirana, V.; McLaren, P. A hybrid algorithm for high speed transmission line protection. IEEE Trans. Power Deliv. 2005, 20, 2422-2428. [CrossRef]

18. Liu, X.; Osman, A.H.; Malik, O.P. Real-time implementation of a hybrid protection scheme for bipolar HVDC line using FPGA. IEEE Trans. Power Deliv. 2011, 26, 101-108. [CrossRef]

19. Nanayakkara, O.; Rajapakse, A.D.; Wachal, R. Traveling-wave-based line fault location in star-connected multi-terminal HVDC systems. IEEE Trans. Power Deliv. 2012, 27, 2286-2294. [CrossRef]

20. Nanayakkara, O.; Rajapakse, A.D.; Wachal, R. Location of DC line faults in conventional HVDC systems with segments of cables and overhead lines using terminal measurements. IEEE Trans. Power Deliv. 2012, 27, 279-288. [CrossRef]

21. Saha, M.M.; Izykowski, J.J.; Rosolowski, E. Fault Location on Power Networks; Springer Science \& Business Media: London, UK, 2009; pp. 1-432.

22. Leterme, W.; Beerten, J.; van Hertem, D. Nonunit protection of HVDC grids with inductive DC cable termination. IEEE Trans. Power Deliv. 2016, 31, 820-828. [CrossRef]

23. Zheng, X.; Tai, N.; Yang, G.; Ding, H. A transient protection scheme for HVDC transmission line. IEEE Trans. Power Deliv. 2012, 27, 718-724. [CrossRef]

24. Liu, X.; Osman, A.; Malik, O. Hybrid traveling wave/boundary protection for monopolar HVDC line. IEEE Trans. Power Deliv. 2009, 24, 569-578. [CrossRef]

25. De Kerf, K.; Srivastava, K.; Reza, M.; Bekaert, D.; Cole, S.; van Hertem, D.; Belmans, R. Wavelet-based protection strategy for DC faults in multi-terminal VSC HVDC systems. IET Gener. Transm. Distrib. 2011, 5, 496-503. [CrossRef]

26. Zheng, Z.; Tai, N.; Thorp, J.S.; Yang, G. A transient harmonic current protection scheme for HVDC transmission line. IEEE Trans. Power Deliv. 2012, 27, 2278-2285.

27. Hajian, M.; Zhang, L.; Jovcic, D. DC transmission grid with low-speed protection using mechanical DC circuit breakers. IEEE Trans. Power Deliv. 2015, 30, 1383-1391. [CrossRef] 
28. Azad, S.P.; Leterme, W.; van Hertem, D. A DC grid primary protection algorithm based on current measurements. In Proceedings of the 17th IEEE European Conference on Power Electronics and Applications (EPE15 ECCE-Europe), Geneva, Switzerland, 8-10 September 2015; IEEE: Geneva, Switzerland, 2015; pp. 1-10.

29. Abu-Elanien, A.E.; Elserougi, A.A.; Abdel-Khalik, A.S.; Massoud, A.M.; Ahmed, S. A differential protection technique for multi-terminal HVDC. Electr. Power Syst. Res. 2016, 130, 78-88. [CrossRef]

30. Valipour, M. Optimization of neural networks for precipitation analysis in a humid region to detect drought and wet year alarms. Meteorol. Appl. 2016, 23, 91-100. [CrossRef]

31. Valipour, M.; Banihabib, M.E.; Behbahani, S.M.R. Comparison of the ARMA, ARIMA, and the autoregressive artificial neural network models in forecasting the monthly inflow of Dez dam reservoir. J. Hydrol. 2013, 476, 433-441. [CrossRef]

32. Mirzaei, M.; Ab Kadir, M.; Moazami, E.; Hizam, H. Review of fault location methods for distribution power system. Aust. J. Basic Appl. Sci. 2009, 3, 2670-2676.

33. Silva, K.; Souza, B.; Brito, N. Fault detection and classification in transmission lines based on wavelet transform and ANN. IEEE Trans. Power Deliv. 2006, 21, 2058-2063. [CrossRef]

34. Martín, F.; Aguado, J.A. Wavelet-based ANN approach for transmission line protection. IEEE Trans. Power Deliv. 2003, 18, 1572-1574. [CrossRef]

35. Le Blond, S.; Bertho, R.; Coury, D.; Vieira, J. Design of protection schemes for multi-terminal HVDC systems. Renew. Sustain. Energy Rev. 2016, 56, 965-974. [CrossRef]

36. Le Blond, S.P.; Deng, Q.; Burgin, M. High frequency protection scheme for multi-terminal HVDC overhead lines. In Proceedings of the 12th IET International Conference on Developments in Power System Protection (DPSP 2014), Copenhagen, Denmark, 31 March-3 April 2014; IET: Copenhagen, Denmark; pp. 1-5.

37. Zou, J.; Han, Y.; So, S.S. Overview of artificial neural networks. In Artificial Neural Networks; Humana Press: New York, NY, USA, 2008; Volume 458, pp. 14-22.

38. Tu, J.V. Advantages and disadvantages of using artificial neural networks versus logistic regression for predicting medical outcomes. J. Clin. Epidemiol. 1996, 49, 1225-1231. [CrossRef]

39. Johnson, J.M.; Yadav, A. Complete protection scheme for fault detection, classification and location estimation in HVDC transmission lines using support vector machines. IET Sci. Meas. Technol. 2017, 11, $279-287$. [CrossRef]

40. Keshri, J.P.; Tiwari, H. Fault classification in VSC-HVDC transmission system using machine learning approach. In Proceedings of the 8th International Conference on Power Systems (ICPS), Jaipur, India, 20-22 December 2019; IEEE: Jaipur, India; pp. 1-6.

41. Muzzammel, R. Machine learning based fault diagnosis in HVDC transmission lines. In Intelligent Technologies and Applications. INTAP 2018, Communications in Computer and Information Science; Bajwa, I.S., Kamareddine, F., Costa, A., Eds.; Springer: Singapore, 2018; Volume 932, pp. 496-510.

42. Van Hertem, D.; Gomis-Bellmunt, O.; Liang, J. HVDC Grids: For Offshore and Supergrid of the Future; John Wiley \& Sons: Hoboken, NJ, USA, 2016; pp. 1-528.

43. Callavik, M.; Blomberg, A.; Häfner, J.; Jacobson, B. Break-through!: ABB's hybrid HVDC breaker, an innovation breakthrough enabling reliable HVDC grids. Abb. Rev. 2013. Available online: https://www.researchgate.net/publication/297049686_Break-through_ABB \T1\textquoterights_ hybrid_HVDC_breaker_an_innovation_breakthrough_enabling_reliable_HVDC_grids (accessed on 13 December 2020).

44. Vapnik, V.N. Statistical Learning Theory; Wiley: New York, NY, USA, 1998; p. 736.

45. Cortes, C.; Vapnik, V. Support-vector networks. Mach. Learn. 1995, 20, 273-297. [CrossRef]

46. Haykin, S. Neural Networks: A Comprehensive Foundation, 2nd ed.; Prentice Hall PTR: Upper Saddle River, NJ, USA, 1998; p. 842.

47. Ren, J. ANN vs. SVM: Which one performs better in classification of MCCs in mammogram imaging. Knowl. Based Syst. 2012, 26, 144-153. [CrossRef]

48. Wu, X.; Wang, D.; Cao, W.; Ding, M. A genetic-algorithm support vector machine and D-S evidence theory based fault diagnostic model for transmission line. IEEE Trans. Power Syst. 2019, 34, 4186-4194. [CrossRef]

49. Zhang, M.; Wang, H. Fault location for MMC-MTDC transmission lines based on least squares-support vector regression. J. Eng. 2019, 2125-2130. [CrossRef] 
50. Lala, H.; Karmakar, S.; Singh, A.K. MATLAB-based GUI development for the detection and localization of faults in transmission line. In Proceedings of the IEEE Region 10 Symposium (TENSYMP), Kolkata, India, 20-22 December 2019; IEEE: Kolkata, India; pp. 654-659.

51. Wang, Q.; Yu, Y.; Ahmed, H.O.A.; Darwish, M.; Nandi, A.K. Fault Detection and Classification in MMC-HVDC Systems Using Learning Methods. Sensors 2020, 20, 4438. [CrossRef]

52. Baghaee, H.R.; Mlakić, D.; Nikolovski, S.; Dragicević, T. Support vector machine-based islanding and grid fault detection in active distribution networks. IEEE J. Emerg. Sel. Top. Power Electron. 2020, 8, 2385-2403. [CrossRef]

53. Baghaee, H.R.; Mlakić, D.; Nikolovski, S.; Dragičević, T. Anti-islanding protection of PV-based microgrids consisting of PHEVs using SVMs. IEEE Trans. Smart Grid 2020, 11, 483-500. [CrossRef]

54. Hsu, C.W.; Lin, C.J. A comparison of methods for multi-class support vector machines. IEEE Trans. Neural Netw. 2002, 13, 415-425.

55. Jackson, J.E. A Users Guide to Principal Components; John Wiley \& Sons: New York, NY, USA, 2004.

56. Peralta, J.; Saad, H.; Dennetière, S.; Mahseredjian, J. Dynamic performance of average-value models for multi-terminal VSC-HVDC systems. In Proceedings of the Power and Energy Society General Meeting, San Diego, CA, USA, 22-26 July 2012; IEEE: San Diego, CA, USA; pp. 1-8.

57. Liang, J.; Jing, T.; Gomis-Bellmunt, O.; Ekanayake, J.; Jenkins, N. Operation and control of multi-terminal HVDC transmission for offshore wind farms. IEEE Trans. Power Deliv. 2011, 26, 2596-2604. [CrossRef]

58. Wang, M.; Beerten, J.; van Hertem, D. Frequency domain based DC fault analysis for bipolar HVDC grids. J. Mod. Power Syst. Clean Energy 2017, 5, 548-559. [CrossRef]

59. Raza, A.; Dianguo, X.; Yuchao, L.; Xunwen, S.; Williams, B.; Cecati, C. Coordinated operation and control of VSC based multi-terminal high voltage DC transmission systems. IEEE Trans. Sustain. Energy 2016, 7, 364-373. [CrossRef]

60. Raza, A.; Liu, Y.; Rouzbehi, K.; Jamil, M.; Gilani, S.O.; Dianguo, X.; Williams, B.W. Power dispatch and voltage control in multi-terminal HVDC systems: A flexible approach. IEEE Access 2017, 5, 24608-24616. [CrossRef]

Publisher's Note: MDPI stays neutral with regard to jurisdictional claims in published maps and institutional affiliations.

(C) 2020 by the authors. Licensee MDPI, Basel, Switzerland. This article is an open access article distributed under the terms and conditions of the Creative Commons Attribution (CC BY) license (http://creativecommons.org/licenses/by/4.0/). 